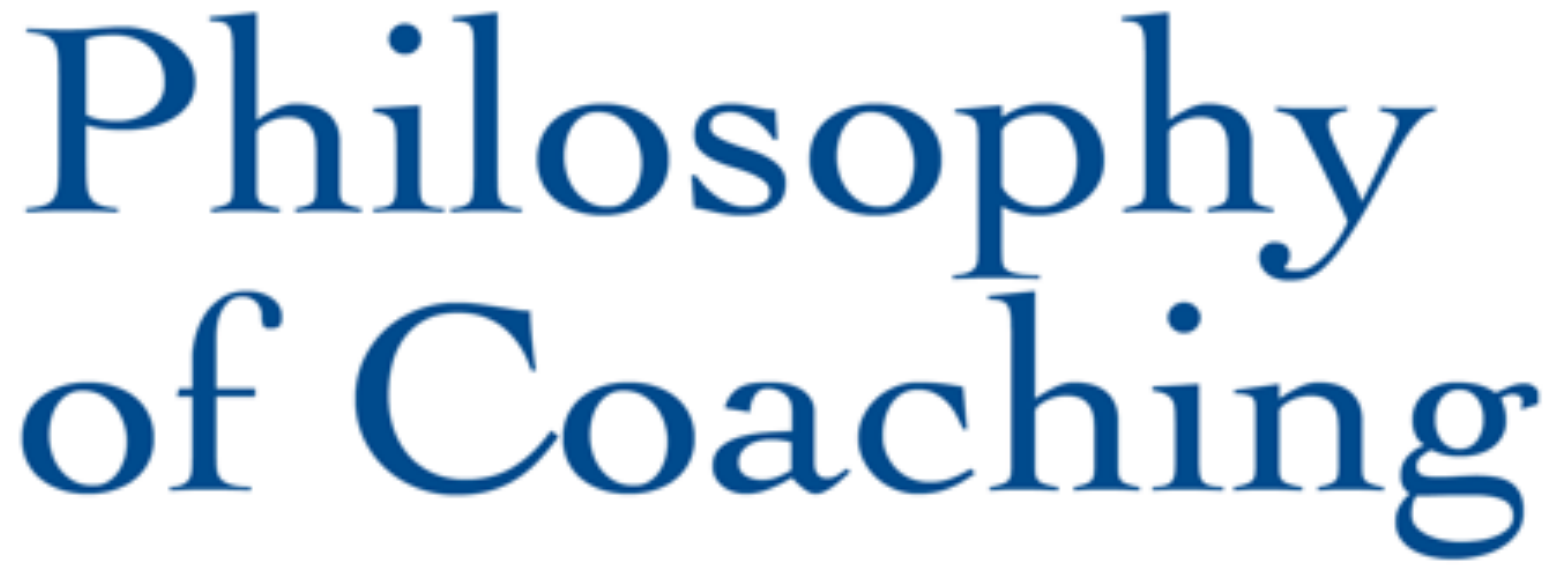

An International Journal

Volume 4, Number 2

November 2019 


\section{Editor's Introduction}

Welcome to the seventh issue of the peer reviewed, open access academic journal Philosophy of Coaching, and to the first issue that we have edited together.

Now feels like an appropriate opportunity to acknowledge the foundational efforts of Dr Julian Humphreys, who recognised the need for a new forum for sharing ideas and perspectives about coaching and challenging prevailing assumptions. After grasping the initial opportunity, Julian has invested several years of hard work in getting this journal up and running. We offer our thanks to Julian and hope we are successful in taking on his mantle.

In our first issue we have not focused on a specific theme. Instead, in our Call for Papers, we invited submissions on any and all topics relevant to the purpose of the journal, which is to further our collective understanding as to what coaching is, what coaching can become, and how coaching can have a positive impact on society as a whole.

The coaching industry is a diverse and eclectic community, and we encourage those with insights from different domains to share their ideas and philosophies in service of further developing the field. The coaching industry, it seems to us, has reached the latest in a series of crossroads, a point at which some continue to urge us all to choose the traditional 'professional' path, with its focus on establishing boundaried fields of knowledge and on defining coaching in terms of a finite list of competencies. The risks of choosing such a route include the devaluation of alternative perspectives and a subsequent impoverishment of coaching as a force for good. We chose to take on editorship of the journal to further promote a forum for creativity and challenge, without requiring the reporting of original experimental research. We know many practitioners out there who have something valuable to say, but may not have the resources to conduct research.

This edition of the journal includes three articles and three book reviews.

In the first paper, Alicia Hullinger, Joel DiGirolamo and Thomas Tkach report the outcome of a literature review on the themes of reflection, awareness and self-regulation. The outcome of their review is the Reflective Practice Model, a framework that positions the three themes in a single framework, a 
framework that constitutes a set of skills to be learned, skills that enable a coach to enhance their capacity to facilitate reflection.

In the second paper, Paul Lawrence notices the emergence of the term 'systemic coaching' as a response to the increasing complexities of the worlds in which we operate. Whilst the need for coaches to think more holistically is widely recognised, there is less discourse as to what we more specifically mean when we talk about 'systems' and 'systems thinking'. Lawrence encourages coaches to familiarise themselves with relevant thinking from the worlds of management science and organisational development, and to determine their own personal philosophies as self-as-systemic-coach.

In the final paper, Erek Ostrowski reports on outcomes from group coaching with entrepreneurs and in a graduate school learning environment. Ostrowski found that group coaching facilitates individual learning and change over time through a social process. Opportunities to engage in vicarious learning and to receive feedback from peers, distinguishes group coaching from individual coaching and makes group coaching a particularly useful component of graduate business programs.

The three book reviews include Cat Dunne's review of Peer Supervision in Coaching and Mentoring. A Versatile Guide for Reflective Practice by Tammy Turner, Michelle Lucas and Carol Whitaker (2018), Keegan Luiters' review of Transformational Coaching to Lead Culturally Diverse Teams by Sunny Stout Rostron (2019), and Gordon Spence's review of Coaching and Mentoring Research. A Practical Guide by Lindsay Oades, Christine Leanne Siokou and Gavin Slemp (2019).

In closing, we would like to invite you to help us build the scope and reach of the journal by telling your colleagues about it and encouraging them to subscribe (for free) at philosophyofcoaching.org/subscribe. In addition, we warmly invite you to contribute to the content of the journal, by submitting a paper for peer-review and advancing the intellectual development of coaching.

We hope you enjoy this issue of the journal.

Paul Lawrence PhD and Gordon Spence PhD

Co-Editors 


\section{Editorial Board}

\section{Founder}

Julian Humphreys Ph.D.

\section{Editors-in-Chief}

Paul Lawrence Ph.D.

Gordon Spence Ph.D.

\section{Senior Advisory}

Tatiana Bachkirova Ph.D. - Oxford Brookes University

Richard Boyatzis Ph.D. - Case Western Reserve University

Joan M. Batista Foguet Ph.D. - ESADE

Konstantin Korotov Ph.D. - ESMT Berlin

James Pawelski Ph.D. - University of Pennsylvania

Sunny Stout-Rostron Ph.D. - University of Stellenbosch

\section{Publishing Advisory}

Suzi Pomerantz - Library of Professional Coaching

\section{Editorial Panel}

Geoff Abbott Ph.D.

Pauline Fatien Diochon Ph.D.

Judie Gannon Ph.D.

Travis Kemp Ph.D.

Tom Krapu Ph.D.

Amanda Matejicek Ph.D.

Elizabeth McCourt J.D.

Sean O'Connor Ph.D.

Reinhard Stelter Ph.D.

Simon Western Ph.D.

Angela Wright 


\section{Table of Contents}

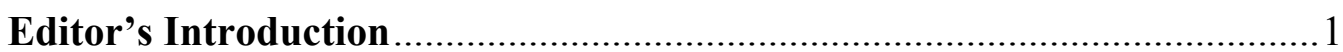

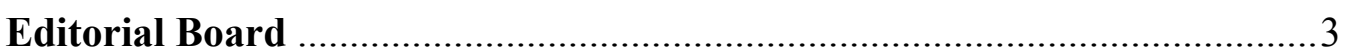

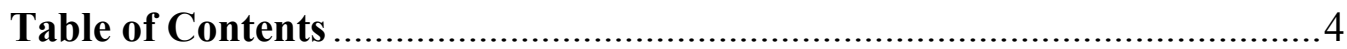

Reflective Practice for Coaches and Clients: An Integrated Model for Learning

Alicia Hullinger, Joel A. DiGirolamo \& Thomas Tkach...................................5

What is Systemic Coaching?

Paul Lawrence.

Using Group Coaching to Foster Reflection and Learning in an MBA Classroom

Erek J. Ostrowski

Book review: Peer Supervision in Coaching and Mentoring. A Versatile

Guide for Reflective Practice by Tammy Turner, Michelle Lucas \& Carol Whitaker

Reviewed by Cat Dunne

Book review: Transformational Coaching to Lead Culturally Diverse Teams by Sunny Stout-Rostron

Reviewed by Keegan Luiters

Book review: Coaching and Mentoring Research: A Practical Guide by Lindsay Oades, Christine Siokou \& Gavin Slemp

Reviewed by Gordon Spence. 


\title{
Reflective Practice for Coaches and Clients: An Integrated Model for Learning
}

\author{
Alicia M. Hullinger ${ }^{1}$ \\ Lexington, USA \\ Joel A. DiGirolamo ${ }^{1}$ \\ Lexington, USA
}

\section{J. Thomas Tkach \\ Lexington, USA}

\begin{abstract}
The literature on reflection, awareness, and self-regulation provides theoretical and empirical fruit for understanding self-processing mechanisms that enhance learning, growth, and performance. A literature review was conducted to explore the potential of reflection, awareness, and self-regulation as developmental tools for coaches. From the review, an integrated Reflective Practice Model was created to help coaches understand these three self-processing mechanisms as an integrated skill set for facilitating personal and professional growth for both the coach and client. The model assumes that reflection and awareness are antecedents to selfregulation. Each term is conceptualized as a skill that can be learned. This model may be used for reflection inward (internal), awareness to personal actions or emotions, and enhanced self-regulation. Reflection upon past events is considered a generalized application, however, the model may also be used in the moment of a discussion. Similarly, the model may be used by a coach to influence client reflection, self-awareness and self-regulation. While others have written about these concepts, to date no one has compiled these elements into a single, integrated model.
\end{abstract}

Keywords: coaching, self-reflection, self-awareness, self-regulation, adult learning

\section{Introduction}

Researchers have looked at the concepts of reflection, awareness, and self-regulation as skills for enhancing personal and professional well-being,

\footnotetext{
${ }^{1}$ The first and second authors are considered to have contributed equally to this work.
} 
learning and change. These terms have been conceptualized by scholarly practitioners as states, traits, processes, and interventions (Vago \& Silbersweig, 2012). Conceptualized separately and interrelatedly, the constructs are a combination of perceptual, cognitive, emotional, and behavioral neurological processes. Reflection is generally viewed as a thinking activity, whereas awareness broadly refers to insight. Self-regulation commonly encompasses the practice of control. In this work we will be referring to the three concepts as both processes and skills, where the process is when the individual is applying the particular skill.

The literature tends to separate out these skills but indicates that each activity is an important factor in a multitude of positive outcomes such as enhanced learning (Mamede \& Schmidt, 2004), well-being (Branson, 2007), physical health (Richards, Campenni, \& Muse-Burke, 2010), emotional intelligence (Brown, Ryan, \& Creswell, 2007), interpersonal relationships (Vohs \& Baumeister, 2016), and goal attainment (Vohs \& Baumeister, 2016). Extrapolating from research in the fields of adult education, psychotherapy, nursing, and management, these three skills have the potential to enhance a coach's efficacy and client outcomes.

Professional coaches often work in high stakes environments and with individuals who desire to maximize their potential. Organizations and individuals who hire coaches expect positive outcomes from their coaching. Researchers have been working to establish a foundation of empirical research to help coaches understand what factors contribute to positive outcomes for their clients and to help the field mature (e.g. de Haan, Duckworth, Birch, \& Jones, 2013; Jones, Woods, \& Guillaume, 2016; McKenna \& Davis, 2009; Sonesh, Coultas, Marlow, Lacerenza, Reyes, \& Salas, 2015; Theeboom, Beersma, \& van Vianen, 2014). While empirical research has been used by the industry to set a benchmark for effective coaching practice, not much attention has been given to how coaches maintain their skills in order to achieve positive outcomes for their clients.

Professional associations in the field, including the European Mentoring \& Coaching Council (EMCC, 2015) and International Coach Federation (ICF, n.d.), along with some researchers (Blumberg, 2014; Vandaveer, Lowman, Pearlman, \& Brannick, 2016) have developed competency models to set a benchmark for effective coaching and to promote professionalization. One of the areas of overlap among these competency models for coaches is professional development of the coach. Whether it's a requirement or not, many 
professional coaches go through training programs and earn continuing education credits to reach and maintain a certain level of proficiency.

The following research demonstrates the usefulness of reflection, awareness, and self-regulation concepts for the field of coaching. A literature review was conducted to explore the potential use of these skills as tools for coaches to maintain their coaching skills and to facilitate learning and growing opportunities for their clients. The existing literature was used to create an integrated Reflective Practice Model to help coaches understand how these three processes work together as a skill set for learning and change. The underlying philosophy of the model draws on adult learning theory (Merriam, 2011). The model provides a good framework for coaches to examine their selfdevelopment and how it can improve their relationship with others as well as be more effective at supporting clients in their learning.

In the model, reflection, awareness, and self-regulation skills are seen as separate but interconnected tools that can be used in the coaching process. The model is holistic in two ways. First, the model views each of the constructs as a single processing system of interaction. Second, the model accounts for both coach and client and their contexts. Applications for both coaches and clients are identified. This model is an attempt to shed light on a learning activity that is at the heart of coaching, for both coaches and clients alike, in a simple, explicit way. In doing so, the profession deepens its own awareness and holds that awareness in service to the client.

\section{Reflection}

Reflection has been of interest to scholars as a skill for improving learning outcomes. Different terms have been used to interpret the concept, such as reflection-in-action, reflection-on-action, self-monitoring, and selfregulation, all of which are used interchangeably (Moon, 2013). Studies on selfreflection have been conducted in the areas of nursing, teaching, education, mental health, and management. The literature can be broken down into definitions, benefits, coaching literature interpretation, and strategies for development of the term.

Several key theorists have examined the processes of reflection (Boud, Keogh, \& Walker, 1985; Mezirow, 1990; Schön, 1983). This line of thinking is linked to the philosophies of Dewey (1933/1997), Freire (1970), and Habermas (1984). We see that reflection is for the adult learner (Boud et al, 1985; Dewey, 1933/1997; Mezirow, 1990), the practitioner (Schön, 1983), and the social 
change agent (Habermas, 1984; Freire, 1970). The underlying principles of these emancipatory philosophies offer a means of reflection and critique of power in order to reframe the traditional view on the essence of being and doing. Coaching, as an evidence-based practice and social movement (Spence, 2007), builds upon and expands these principles in order to transform individuals, groups, organizations, communities, and society.

\section{Definition}

Definitions for reflection tend to cite John Dewey (1933/1997), Donald Schön (1983) and Boud et al. (1985). For Dewey, reflection referred to "assessing the grounds of one's beliefs," or the process by which an individual rationally examines their assumptions (p. 9). Schön (1983) distinguished between two types of reflection: reflection-in-action and reflection-on-action. Schön's distinction adds a temporal feature to the interpretation. Reflection-inaction takes place while a person is involved in a situation, during which they observe what they are thinking, feeling, and doing. In contrast, reflection-onaction involves a stepping back from the situation, meaning that it takes place after the experience has occurred. Boud et al. (1985) referred to reflection as "a generic term for those intellectual and affective activities in which individuals engage to explore their experiences in order to lead to new understandings and appreciation." (p. 19). From these definitions, reflection is an active, purposeful thinking process for learning and growing through experience.

It is important to note that reflection has taken on various interpretations. This means that conceptualizations emphasize different elements of reflection, including: self-conscious traits (Fenigstein, Scheier, \& Buss, 1975), stages of reflection (Gibbs, 1988), types of reflection (Grant, Franklin, \& Langford 2002), personal characteristics (Aukes, Geertsma, Cohen-Schotanus, Zwierstra, \& Slaets, 2007), and constructive and counterproductive features of thinking (Trapnell \& Campbell, 1999). While the interpretations may vary, scholars look at reflection as an important strategy for learning and change.

Drawing on both theory and practice, Moon (2013) suggests that reflection is a mental process with a purpose or an outcome. This means, reflection is an ongoing practice that takes time to cultivate. Taking time to reflect means revisiting experiences from multiple perspectives in order to identify past emotions and behaviors and to excavate underlying beliefs and assumptions. Returning to experiences without judgment (Baer, Smith, Hopkins, Krietemeyer, \& Toney, 2006) allows a person to gain new insights to 
help them grow. The process is one of engagement while the outcome is one of clarity.

\section{Benefits}

Self-reflection is thought to play an important role in learning outcomes (Argyris, 1991). The literature on nursing, education, and public health indicates that self-reflection brings about deeper understanding of self-concept, enrichment of learning outcomes, and enhancement of critical thinking skills (Mann, Gordon, \& MacLeod, 2009; Osterman \& Kottkamp, 2004). Selfknowledge gained through the reflective process, or digging deep to understand a situation, helps an individual gain clarity. What we see from this research is that reflection enhances the learning process.

\section{Coaching literature}

Scholar practitioners in the coaching world have theorized on the importance of reflection for the profession (Bachkirova, 2016; Passmore, McMahon, Brennan, Lee, Christian, \& Tenzyk, 2011). Kilburg (2000) maintains that creating a reflective containment, or a safe place where both coach and client can go to process a situation reflectively, is one of the most valuable aspects of coaching. As Bennett \& Rogers (2011) state: "It is through reflection that practitioners hone their intuitive skills, which is tied to selfawareness, which is tied to confidence and the liberation that comes with the... sense of "being" a coach." (p. 28). This means coaching is not only about the doing (the techniques, methods, approach, or model a coach uses) but also about the being, or the coach's presence by holding the space for the client to make the transformation. It seems that the scholars have borrowed "being" from Hargrove's (1995) assertion on the makings of a masterful coach in which a coach is something that you be. For Harvey (2015), "Being reflective on practice is the most empowering resource available for our professional development because the answers arrive inside-out as gifts of consciousness and give us the power of choice" (p. 3).

\section{How to strategies}

Reflection is a skill that can be learned. Developing reflection as a skill means enhancing an individual's capacity to engage in observation and asking critical questions (Boud et al., 1985). The literature has identified strategies that improve reflection. Practices that have been associated with developing reflection include journaling, storytelling, meditation, mindfulness, and case 
studies (Gray, 2007; Guiffridda, 2015; Woods, 2011). Coaching supervision is another strategy for improving reflection skills (Bachkirova, Jackson, \& Clutterbuck, 2011; Carroll, 2010; Hodge, 2016; McGivern, 2009). A coaching supervisor can help facilitate questions to prompt reflection for the supervisee.

In People Skills, Thompson (2015) suggests that there are six steps to reflection: read the situation to learn, ask others what they are doing and why, watch what is going on, feel internal emotions that come up, talk about views and experiences with others, and think about different situations. When done right, reflection is a constructive, creative, critical thinking strategy for growth.

These strategies require setting aside time to deeply reflect on an experience. Time spent on reflecting means focusing on professional or personal things that matter. Reflection starts by identifying a situation, a case study of the self, that can be used as a learning opportunity. Details are important when observing the experience in the process of reflection. This means taking a look at and being able to describe what happened, what behaviors and emotions were involved, what factors influenced the situation, and what assumptions were in place. Practicing self-reflection means systematically communicating with the self by taking time to ask questions of the self and thinking through issues.

\section{Awareness}

Self-awareness or self-knowledge has been a subject of inquiry of philosophers and psychologists alike. This line of inquiry explores how the brain, cognitive processes, and the social environment construct the selfconcept (Fiske \& Taylor, 2013). The self is an individual's mental picture of who they see themselves as in this world (Markus \& Wurf, 1987). Attention focuses on the significance of self-knowledge in human fulfillment (Fiske \& Taylor, 2013). The adage "know thyself" speaks to the significance of selfknowledge as being the foundation of knowledge itself.

\section{Definition}

In their groundbreaking book, A Theory of Objective Self-Awareness, psychologists Duval and Wicklund (1972) developed a theory for selfawareness, proposing that when an individual focuses their attention on themselves, they evaluate and compare their current behavior to their own internal standards and values. Meaning, we become self-conscious as objective evaluators of ourselves. Later on, Fenigstein (1987) proposed two factors of 
self-awareness: private and public. Private self-awareness refers to an individual's understanding of their internal mental state which is invisible to others, such as thoughts and emotions (Fenigstein, 1987). In contrast, public self-awareness refers to an individual's awareness of their self as viewed by others, or their external state (Fenigstein, 1987).

Self-awareness has been heavily represented in the emotional intelligence literature (Bar-On, 1997; Goleman, 1995; Salovey \& Mayer, 1990). Emotional intelligence refers to the ability to recognize, understand, and control emotions and to understand that emotions can drive behavior and positively or negatively impact others (Salovey \& Mayer, 1990). According to this line of research, enhancing self-awareness means achieving higher emotional intelligence. Selfawareness is also a major mechanism of self-control (O'Donoghue \& Rabin, 2003). Self-control is the ability to regulate the self in the face of temptations and impulses (O’Donoghue \& Rabin, 2003). From these models, self-awareness is one of many factors that contribute to emotional intelligence and self-control (Ackley, 2016). In this current model, self-awareness is an important precursor to self-control.

Self-awareness is an appraisal process taking place in order to achieve insight on the self and others. An individual becomes aware, or gains insight, when they are able to make an accurate appraisal of their abilities and preferences and the implications of their behavior and impact on others (Eurich, 2017; Sutton, 2016). This internal-external awareness lens is an ongoing, iterative process of interaction similar to what is described as complex responsive processes of relating (Stacey \& Griffin, 2006). This complexity science perspective emphasizes human interdependence and views individuals as thoroughly social selves that arise in human interaction (Stacey \& Griffin, 2006). Relating between people produces patterns of human interaction which produce further patterns of interaction (Stacey \& Griffin, 2006).

Engaging in deep reflection can lead to awareness. To become aware of the self means making an assessment of observations that are described in the reflection phase. The judgment-call in the awareness phase is a clear and accurate perception of both the internal self and external others. Awareness is about seeing more clearly. When a person makes an inaccurate assessment of their reflections, the person is not truly aware. Eurich (2017) refers to this as "delusional". 


\section{Benefits}

Since the Korn Ferry Institute (Zes \& Landis, 2013) reported a positive association between self-awareness and a company's rate of return, business and leadership gurus have been promoting self-awareness as a critical skill for professional development. This follows the trend for focusing on intrapersonal skills that followed the works of Mayer and Salovey (1993) and Goleman (1995) who have done extensive research on emotional intelligence.

Researchers and practitioners have distilled the scholar's model into different factors that make up a person's emotional intelligence, including self-awareness (Bratton, Dodd, \& Brown, 2011). Findings have then been used to make claims that it is the secret to leadership success (AMA, n.d.). Self-awareness has been associated with leadership and managerial performance (Avolio \& Gardner, 2005; Church, 1997; Tekleab, Sims, Yun, Tesluk, \& Cox, 2008; Hall, 2004) and job performance in general in the workplace (Humphrey, O'Boyle, Pollack, Hawver, \& Story, 2011; Sutton, Williams, \& Allinson, 2015). Greater empathy and listening skills, improved critical-thinking skills, and better decision making are also associated with greater self-awareness (Eurich, 2017). Selfawareness contributes beneficially to psychological functioning, including creativity and confidence (Silvia \& O'Brien, 2004). Research also shows that self-awareness can benefit those around us - those who are more self-aware report higher-quality relationships (Carlson, 2016).

\section{Coaching literature}

Coaching has taken up self-awareness as established in the emotional intelligence literature to support clients in developing resonant relationships that help them in the learning process (Boyatzis, Smith, Van Oosten, \& Woolford, 2013). Gatling, Castelli, \& Cole (2013) describe self-awareness as playing a significant role in coaching performance for helping clients obtain goals. Tekleab et al. (2008) look at the effect of self-awareness on affective and behavioral outcomes, showing that self-awareness is related to leader effectiveness and the team member's satisfaction of the supervisor. In Coaching Skills: A Handbook, Rogers (2012) uses case studies to show how awareness is an important tool in the coaching process for experienced and beginner coaches alike. Armstrong (2009) argues for an integral coaching that includes both internal and external awareness, or insight and outsight. She emphasizes the significance of outsight, or the ability to take into account the outward complexity of any situation that influences human interactions (Armstrong, 2009). 


\section{How to strategies}

Practices associated with developing awareness include psychometric assessments, meditation, mindfulness, physical self-care, and feedback from others, such as self-monitoring, coaching supervision, mentoring, 360 surveys, and conversations with peers, followers, and superiors (Fogel, 2009; Lawrence \& Whyte, 2014; Richards et al., 2010; Tekleab et al., 2008). The field of coaching has turned to research on mindfulness practice (e.g. Langer, 1989) as a strategy for developing awareness to lead to better outcomes (Kemp, 2016).

For a comprehensive approach to developing or fine-tuning awareness, Eurich (2017) outlines thirty strategies for becoming more aware internally of the self and externally of others. For example, she suggests short, daily checkins to look for patterns and observe what worked and what did not work for the day. For Eurich, seeking the right feedback is important for gaining insight. This means seeking out the right people, i.e. a loving critic, who is willing and able to be brutally honest. Again, working with a coaching supervisor, mentor, or peer can be a strategy for getting external feedback.

Practicing awareness means engaging all the senses and paying attention to what the body is doing, what the mind is thinking, and how the emotions are feeling. Awareness requires an open mind in order to see the good, the bad, and the ugly. Done properly, the practice of awareness cultivates insight in order to express the self with more clarity and purpose.

\section{Self-Regulation}

Much of the research in psychology investigates the association between the ability to regulate one's emotions and various aspects of mental health (Vohs \& Baumeister, 2016). Emphasis tends to be on emotion regulation because emotions trigger fight or flight behavior. If emotions are in check, then behaviors align, according to this line of thinking. Theories have looked at the role of self-regulation on people's lives (Vohs and Baumeister, 2016). Our review of the literature suggests that there is an absence of both consistent, agreed-upon conceptualizations and comprehensive, adequate measures of emotion regulation in adults. For example, a broad use of the term includes research on goal-oriented action (Locke \& Latham, 1990), control (Rotter, 1966), and behavior modification (Skinner, 1974). 


\section{Definition}

Terms such as self-regulation, volition, will-power, and ego-strength have been used in the field of psychology to investigate self-processing mechanisms that control emotions and behaviors (Perrig \& Grob, 2000). For Kuhl \& Fuhrmann (1998), self-regulation is one of two primary modes of volitional competences, or skill of will. As a mode of volition, self-regulation supports the task for maintaining one's actions to be in line with one's integrated self, where self is a representation of experiences, beliefs, and needs.

Thompson (1994) defined emotion regulation as "the extrinsic and intrinsic processes responsible for monitoring, evaluating, and modifying emotional reactions, especially their intensive and temporal features, to accomplish one's goals" (pp. 27-28). Gross (2014) conceptualized emotion regulation as a set of strategies that responds to emotion generation. For Green \& Grant (2003), the tasks involved in self-regulation include setting goals, planning, acting, monitoring, evaluating, and changing emotions or behavior. According to Gratz and Roemer (2004), self-regulation involves: emotional awareness, emotional clarity, emotional acceptance, impulse control, ability to engage in goal-directed behavior while experiencing negative emotions, and ability to use situationally appropriate emotion regulation strategies to moderate emotional responses (pp. 42-43). In these definitions we see a conflation of self-processing mechanisms for self-regulation.

The research on self-regulation is similar to Kolb's (1984) experiential learning cycle model. The experiential learning theory model functions on two levels: a four-stage cycle for learning and four learning styles. Learning starts with a concrete experience then cycles through reflective observation, abstract conceptualization (searching for meaning of experience), and active experimentation (doing things in a different way; Kolb, 1984). The four learning styles are based on how an individual perceives a task (feeling or thinking) and how they process a task (doing or watching; Kolb, 1984). Here, we can start to see the integration of self-processing mechanisms for change.

Goal-directed learning is also an important part of self-regulation processes (Corno \& Kanfer, 1993). Self-regulation is a control mechanism that draws on goal setting and planning in order to react appropriately in a given situation, in a purposeful and meaningful way (Latham \& Locke, 1991). Research shows that making a specific goal and plan increases the likelihood of the action to take place (Kolb \& Boyatzis, 1971; Locke \& Latham, 1990). 
Self-regulation is the reason for all this work, it is the control mechanism for processing emotions and behaviors. When a person has taken the time to deeply reflect in order to become aware of who they are and how others perceive them, then there will be times when the person recognizes experiences where their emotions or behaviors were out of line with their values or the situation. Using this insight to self-regulate means exercising control or modifying present or future emotions or behavior in order to act in accordance with the situation.

\section{Benefits}

Self-regulation is an important factor in efficient social functioning and well-being (Markus \& Wurf, 1987). The ability to regulate emotions and behavior is associated with long-term health benefits (Hall \& Fong, 2007), enhanced relationships, improved interpersonal skills, and better conflict resolution (Vago \& Silbersweig, 2012). Self-regulation has been associated with being more intellectually skilled, more responsible and dependable, and more attentive in the long-term (Goleman, 1995). Learning to control emotions and behaviors leads to greater success in life. The field of education has shown benefits of self-regulation on learning and performance (Schunk \& Zimmerman, 2011).

\section{Coaching literature}

In the coaching literature, self-regulation is viewed from the client's perspective- how a coach can help facilitate self-regulation in a client. For Grant (2012), the self-regulation goal attainment model is a robust technique for coaches to use to facilitate changes in views and behaviors for their clients. As an iterative process, the approach includes setting a goal, developing an action plan, acting, monitoring, evaluating, and then making the appropriate change in perspective or behavior (Grant, 2012). Coaching is viewed as a tool for enhancing mental health, quality of life, and goal attainment (Grant, 2003; Green, Oades, \& Grant, 2006). Research on coaching outcomes has shown that coaching has a positive effect on psychological variables, i.e., self-regulation, self-insight and solution-focused thinking (Theeboom et al., 2014).

\section{How to strategies}

Self-regulation can be considered a strategy to foster positive interactions with self and others. For Grant, Franklin, \& Langford (2002), self-reflection and insight are key factors to self-regulation. This means that strategies for self- 
regulation start with reflection and awareness. A person needs to be in tune with who they are and their values in order to recognize which emotions and behaviors are out of line. Practices that have been associated with developing self-regulation include: goal-setting (Green, Oades, \& Grant, 2006; Pintrich, 2000; Zimmerman, 2000), breathing exercises and mindfulness (Chambers, Gullone, \& Allen, 2009), yoga (Gard, Noggle, Park, Vago, \& Wilson, 2014), self-care (Bandura, 2005), and physical activity (Oaten \& Cheng, 2006). As an important strategy for self-regulating, goal-setting theory claims that writing down concrete, specific goals and strategies can help individuals overcome obstacles and achieve positive outcomes (Locke \& Latham, 1990).

Adult learning theory (Merriam, 2011) and the concepts of reflection, awareness, and self-regulation have been fruitful for the field of coaching (Cox, 2015). From an adult learning perspective, coaching is seen as a way to engage clients with change, or the learning and growth process (Cox, 2015; Pinkavova, 2010). In their work on personal and organizational change, Kegan \& Lahey (2009) bring attention to the barriers to developing new learning, what they refer to as immunity to change. The scholars suggest that individuals have hidden mindsets that get in the way of new learning. The coaching process has been directed at facilitating learning and change in the client (Hargrove, 1995). In this article, we take the practice deeper by turning focus to the coach's professional development, in service to the client.

The coaching field has started to link theoretical knowledge to practice (Cox, Bachkirova, \& Clutterbuck, 2014; Passmore, 2015; Stober \& Grant, 2010), a sign of mastering the craft in order to make claims on the importance of reflection, awareness, and self-regulation in the coaching process. While these processes tend to be separated or conflated, we take previous conceptualizations a step further by integrating reflection, awareness and selfregulation into a simple, interactive model of self-processing mechanisms. A reflective practice can help dig into and understand deeply rooted and hidden mindsets that create a natural but enforcing immunity to change (Kegan \& Lahey, 2009). The purpose of the model presented here is for the profession to reflect on the coach as practitioner, fine tuning themselves as an instrument (Bachikirova, 2016).

\section{A Robust Reflective Practice Model}

The Reflective Practice Model was developed to illustrate to both coaches and clients the mechanisms that foster learning and change. The model assumes that reflection and awareness are antecedents to self-regulation. Each term is 
conceptualized as a skill that can be learned. This means that a person who does not have an innate ability to engage in one of the activities can learn and practice in order to develop the skill. The model is an interactive skill set for facilitating personal and professional development.

We dropped the word "self" from reflection and awareness to account for both the internal self and the external other. This is in line with integral theory that states that our emerging structure of consciousness is characterized by the ability to think and act from multiple worldviews (Wilber, 2000). For the regulation construct, the model accounts for the internal self and not for the external other. We have avoided the automatic and unconscious aspects of these self-processing mechanisms in order to emphasize the conscious actions that can be taken in order to develop an integrated skill set for a robust reflective practice.

From the research on reflection, awareness, and self-regulation, what we see is that the self-processing mechanisms are triggered by an experience as described by Kolb (1984) and Mezirow (1990). An individual may respond in an adaptive or maladaptive way. Since we are interested in positive outcomes, then we focus on the productive operationalization of these processing mechanisms. The model excludes maladaptive emotions and cognitions, such as rumination (Trapnell \& Campbell, 1999) because these type of distortions, judgments, and biases are not going to result in positive self-regulation. Meaning, we emphasize how a person interprets an experience in a meaningful way by observing, questioning, analyzing, synthesizing, and evaluating in order to make a transformation.

Boyatzis' (2006) work on positive and negative emotional attractors can guide our focus on staying in the positive or shifting away from negative territory by trusting resonant relationships. This is because change needs more positivity than negativity (Boyatzis, 2006). Relationships that enable an individual to learn help steer them towards positive adaptations (Boyatzis, 2006). For Boyatzis (2006), intentional change is important to a person's adaptation, and resonant relationships encourage the intention to change. This is where an activity like mindfulness (Langer, 2014) supports being intentional (Boyatzis, 2006).

We used the literature review to develop definitions for the three constructs. For heuristic purposes, we separated the self-processing mechanisms out into three parts (reflection, awareness, and self-regulation) as a 
way to identify the key processes taking place. Figure 1 illustrates an internal use of the integrated skill set and Figure 2 an external use.

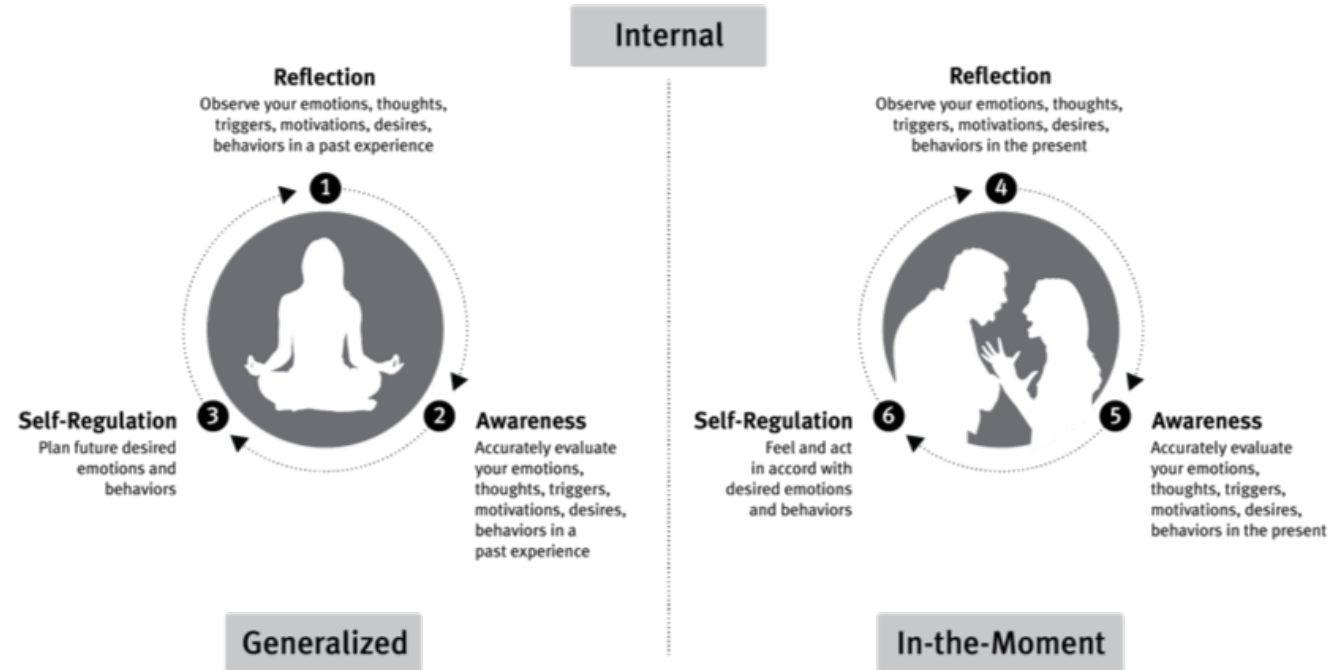

Figure 1. An internal use of the Reflective Practice Model.

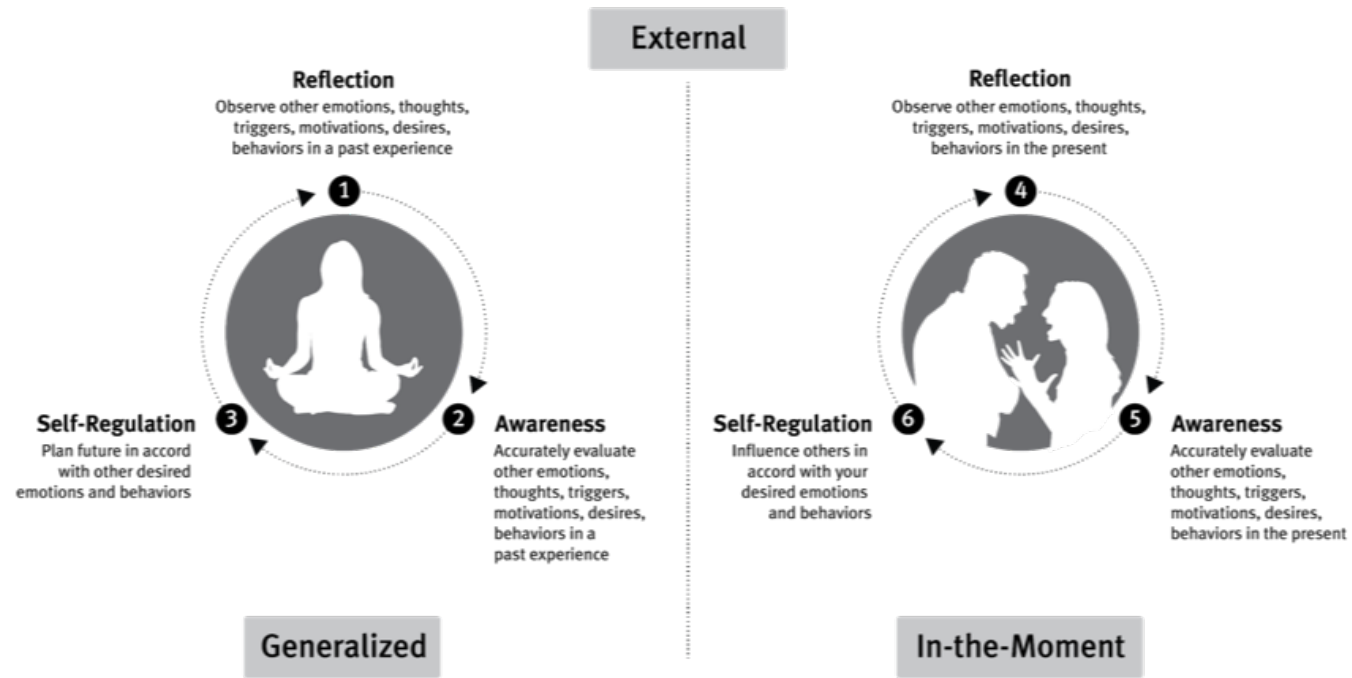

Figure 2. An external use of the Reflective Practice Model.

We included temporal (in-the-moment and generalized) and viewpoint (internal-self and external-other) features for each construct. In-the-Moment processing takes place during an experience related to the action of regulation, 
whereas Generalized occurs in moments temporally separated from the moments related to the action of regulation. Internal processing focuses on the self, whereas external processing turns to others. An event, situation, or experience triggers the self-processing mechanisms.

Starting with reflection, the key actions taking place are contemplating, observing, inspecting, and questioning. Specifically, reflection means to contemplate, observe, inspect, and question without judgment one's past or present experiences to examine one's own character, thoughts, behavior, emotions, beliefs, motivations, and abilities and how others perceive the person. Reflection is primarily about the experience. During or after an experience or event, a person can critically think about a situation. Reflecting in a proactive way emphasizes a non-judgmental perspective. As a maladaptive process, the person may get stuck in reflection, i.e. rumination (Trapnell \& Campbell, 1999). In rumination, they are stuck in their thinking because they start judging the situation and they are not able to move past a negative description of their experience. Rumination potentially prevents awareness, the second stage in the model.

Reflection is used to cultivate awareness - the next step in the model. Awareness is defined as a clear, accurate perception and appraisal of one's past or present character, thoughts, behavior, emotions, beliefs, motivations, abilities and their implications and how others perceive the person. This is primarily about appraisal, which is both a process and an outcome. Proactive awareness means a person assesses a situation and arrives at an accurate conclusion of the meaning of the experience.

Maladaptive awareness, or what Eurich (2017) refers to as delusional, is when someone is not able to make an accurate conclusion of the meaning of that experience - they just do not see any other perspective except their own self-view. Also, someone may stop at awareness, choosing to take no action toward self-regulation.

Once a person is aware of what needs to be improved, the next step is self-regulation. Specifically, self-regulation means to exercise control of or to modify one's present or future emotions and behavior in order to act in accordance with the situation and the person's desired goals and plan (Mischel \& Ebbesen, 1970). Initially self-regulation is cognitive and forced but then the new emotions and behaviors become natural, fluid, and automatic. Resilience and flexibility become factors for individuals in this process (Waugh, Thompson, \& Gotlib, 2011). Self-regulation is primarily about a control 
process. Identifying one's values and goals requires awareness. Setting a plan to make the necessary change in emotions or behavior initiates self-regulation. Here we see overlap between awareness and self-regulation. A person needs to be aware of their own values along with the other person's values in order to align goals and to set a plan that will act in accordance with the situation.

We have looked at self-processing mechanisms from an adaptive perspective. The goal is to deepen reflection and awareness in a way that leads to positive and productive self-regulation. We see lots of moving parts in the process - the internal self is experiencing emotional impulses, thoughts, and feelings in relation to the other who is experiencing their own emotional impulses, thoughts, and feelings. The internal self and other are in a relationship together and with their environment (context) for what is happening in that very moment in addition to all the things from the past and hoped-for future, consciously or subconsciously, that have showed up to join the experience.

We have distilled the significant, overlapping literature into a working model that can be incorporated into the coaching process. The Reflective Practice Model is recursive. The features of the model include temporal (past, present, and future) and viewpoint (internal-self and external-other).

\section{How the Model Works}

Reflection is an engagement process for observing and questioning. Reflection evokes awareness; awareness activates self-regulation. Once selfregulation has occurred, a person can return to reflection by observing and questioning the changed behavior or emotion and new experience. The interactive process for reflecting, gaining awareness, and self-regulating is a learning experience that facilitates change.

As an example, after coaching a client, the coach takes time to sit down and intentionally reflect upon the session. They remember the emotions, thoughts, and triggers that came up during a key point in the coaching and internally ask questions about their experience (reflection). "Why did this emotion come up? Why was I triggered? Does it have to do with my past struggles with the same issue?" After exploring these emotions, thoughts, and triggers, they accurately evaluate them within the context of the session (awareness). Once a coach comes to a conclusion about these questions, the coach starts to plan on ways to regulate their emotions, thoughts, and triggers in the future (self-regulation). Perhaps a breathing technique can be used. This would be an example of a generalized, internal reflective practice. 
A coach can introduce this model to their clients without explicitly showing them the figure. Probing questions and insightful observations can be communicated to the client in a way that enhances the client's reflection. For example, the coach can ask "what thoughts or emotions arise when you think about this situation?" Once the client reflects upon this, the coach can help the client draw accurate awareness about the situation. Questions that challenge the client's assumptions and biases could help ensure that a more accurate interpretation is reached: "What else could be true?" or "How might an outside observer see this situation?" Finally, the coach can help the client to act in response to the situation. This may involve reframing a belief or making a behavioral change: "How could you reframe that belief in a way that better serves you?" or "How can you bring about this change?" At the end of the session, the coach can ask the client to share the process they went through to arrive at their action plan.

Adhering to an integrated approach to professional development, the model can also be of value to coaching supervision. For clients, coaching is a "sanctuary in which people can take time to focus on themselves and gain insight into behaviors and actions" (Armstrong, 2009, p. 35). Similarly, coaching supervision provides coaches a safe space to support the coach in their own reflective practice. In turn, the Reflective Practice Model, provides a tool for "supervisor self-reflection" in which the supervisor attends to their own internal processes interacting with external relational processes (Hawkins, 2014). Hawkins (2014) suggests that coaching supervision is "a place of cocreative and generative thinking where new learning is being forged for clients, coach and supervisor and for the profession" (p. 402).

Understanding the Reflective Practice Model, coaching supervisors can facilitate growth within the coach at any stage of the process (i.e. reflection, awareness, self-regulation). This can help coaches develop a keener eye to notice subtle changes in emotion, thought, and behavior within themselves as well as their clients (reflection). Supervisors can challenge the coach's assumptions when evaluating these changes in order to arrive at a more accurate interpretation (awareness). And finally, they can help coaches create strategies to work with these changes in a way that best benefits the coach, and in turn, their client (self-regulation).

From our anecdotal experiences as practitioners, educators, and researchers, the model has emerged as a tool that we have applied in our everyday. We find ourselves saying, "let me reflect on that" in our conversations and, then, pausing to take time to observe our thoughts, feelings, 
and behaviors. We have tapped into a deeper awareness, which has enriched our relationship as a unit, helping us to see where we each are coming from, what is important, what might be getting in the way, and acting accordingly. We hope the model can help coaches in their own reflective practice, and in turn, their clients.

\section{Co-Creating a Robust Reflective Practice}

Reflective practice creates the conditions for learning, growth, and performance for both coach and client alike. As an integrated skill set for learning and change, reflective practice can promote well-being for a coach, and consequently, for a client.

Through an integrated reflective practice, coaches can become more in tune with themselves, and in turn, with their clients. A robust reflective practice can help coaches truly tune into the client's agenda. By reflecting on a session (in the moment or generalized in the past) coaches can observe their own interactions and reactions to their clients - that is, their emotions, thoughts, triggers, motivations, desires, and behaviors. Observing the interactions between the self (coach) and the other (client) with a critical eye allows coaches to evaluate the situation. If the goal is to show up fully for the client, but coaches see and feel themselves wandering off, judging, or advising, then they know they are not in alignment with their goal-tuning into the client's agenda. Awareness is an accurate assessment of when interactions went astray from the coach's desire to be fully present for their client. Self-regulation is the disciplinary control mechanism that can help coaches return to their client in the moment or plan how to manage those wandering moments in the future. Reflective practice is an intentional monitoring and evaluation approach to learning and change.

Research on coaching outcomes indicates that the coach-client relationship is one of the most important factors for effective results (de Haan et al., 2013; Baron \& Morin, 2009; Gan \& Chong, 2015). Co-creating a relationship requires an open, flexible, and confident coaching presence, which requires being fully conscious, communicating effectively, and deep listening. A presence that exhibits unconditional positive regard towards a client, creates a safe space for the client to be vulnerable. Showing up and being fully available for the client, in turn, creates trust and intimacy-important factors for a quality relationship. 
Engaging in reflective practice can help cultivate this quality coach-client relationship. Reflection enhances the ability to observe emotions and behaviors of the client. Observing in this way contributes to deep listening - picking up on all the meanings, verbally and non-verbally, coming into play in a coaching session. The integrated reflection skills translate to really listening and paying attention to the client. Noticing subtle movements and tones of the client, becoming fully aware of the client's perspective, being able to moderate any urges that may arise while the client is talking all help a coach to be actively listening.

By engaging in reflective practice, a coach models the way for transformation for their client. Coaches can also share this strategy to facilitate a client's learning and growth. Sharing with clients how the process works is an opportunity to create a space of safety and vulnerability. Letting clients know that coaches have off days too shows the reality of being human. Walking through the reflection, awareness, and self-regulation process with the client using metaphor or a personal example can help both coach and client learn and grow together.

One of the strategies cited across the literature for enhancing each selfprocessing mechanism is mindfulness. Research shows that regular mindfulness practices, such as meditation, have many mental health benefits, such as stress reduction, reduced levels of anxiety and depression, increased happiness and peace of mind, increased concentration, and greater self-acceptance (NIH, 2017; Salazar, 2018). Regular meditation also has many physical benefits, including better sleep, lower blood pressure, stronger immune system, and improved cardiovascular health (Grossman, Niemann, Schmidt, \& Walach 2004). A regular meditation or mindfulness practice can enhance reflection, awareness, and self-regulation.

\section{Conclusion}

This research explores the merits for three self-processing skills to enhance coaching effectiveness. A review of the literature indicates that while the terms reflection, awareness, and self-regulation have their own conceptualizations, definitions, scales, and measures, there is considerable overlap among the three skills. Consequently, these terms often have been conflated with one another. Despite the conceptualization chaos, the literature indicates that each of the concepts are important tools for both personal and professional development. 
While all of the individual pieces of the model have been researched significantly, no one has put all of the pieces together until this article. We synthesized the literature to create an integrated model that accounts for the three self-processing mechanisms working together. For our model, we identified the key actions from the definitions that distinguishes each selfprocessing mechanism. Taking time to reflect means looking inward and seeing what is going on with the self and others. Reflection helps to build awareness and self-regulation, two components of emotional intelligence (Goleman, 1995). Having the ability to be aware means understanding personal values, motivations, goals, strengths, weaknesses, emotions, and behaviors while recognizing their impact on others. Self-regulation involves the ability to control or redirect disruptive emotions and impulses and adapt to circumstances and changes.

The research indicates that each of the three skills returns a range of benefits, including higher quality physical and mental health, improved job performance, and higher quality learning outcomes. Taken together, the selfprocessing mechanisms can be used to address life challenges and to achieve positive personal and professional outcomes. This skill set can be used to manage problems, accomplish goals, boost confidence, reduce stress, be happier, and strengthen relationships. We saw that practices, such as mindfulness, show up as strategies for improving each of the constructs. Also, coaching supervision is perhaps an underutilized professional development activity that has the potential to help the field engage in a comprehensive approach to a robust reflective practice that serves coaches and extends to their clients, having a ripple of influence.

Adult learning theory (Merriam, 2011) helps us examine professional development and see how adults can enhance their learning to bring about change. The fields of education, psychology, and management provide many concepts useful to understanding adult learning. With the observations presented here along with empirical research, we conclude that reflection, awareness, and self-regulation are important skills that have the potential to enhance the coaching process - for both coach and client alike.

For future research, a time-series experimental design can be used to identify the links and the disconnects among the three processes. Future considerations can also explore the implications the model may have on different cultural settings. Another area for future research is client outcomes to better understand to what extent a coach's reflective practice contributes to factors related to their clients. 
Harnessing the self-processing mechanisms of reflection, awareness, and self-regulation can help both coaches and clients to learn about themselves, provide language for their internal and external experiences, and offer tools to navigate interactions in a positive way. As a strategy for learning and change, coaches can use reflective practice to ensure that they continue to strengthen their coaching practice throughout their career. Coaches can also share with clients the workings of a robust reflective practice to serve the client's agenda. Engaging in a robust reflective practice is important to both a coach's and client's learning along with their personal well-being and self-care. We are familiar with the common saying: "be the change that you want to see in the world." A robust reflective practice can help both coaches and clients be that change.

\section{References}

Ackley, D. (2016). Emotional intelligence: A practical review of models, measures, and applications. Consulting Psychology Journal: Practice and Research, 68(4), 269-286.

American Management Association (AMA). (n.d.). New study shows nice guys finish first. Retrieved from http://www.amanet.org/training/articles/newstudy-shows-nice-guys-finish-first.aspx?pcode $=\mathrm{XCRP}$.

Argyris, C. (1991). Teaching smart people how to learn. Harvard Business Review, 69(3), 5-15.

Armstrong. H. (2009). Integral coaching: Cultivating a cultural sensibility through executive coaching. In M. Moral and G.N. Abbott (Eds). The Routlege Companion to International Business Coaching (pp. 34-44). London: Routledge.

Aukes, L. C., Geertsma, J., Cohen-Schotanus, J., Zwierstra, R. P., \& Slaets, J. P. (2007). The development of a scale to measure personal reflection in medical practice and education. Medical Teacher, 29(2-3), 177-182.

Avolio, B. J., \& Gardner, W. L. (2005). Authentic leadership development: Getting to the root of positive forms of leadership. The Leadership Quarterly, 16(3), 315-338.

Bachkirova, T. (2016). The self of the coach: Conceptualization, issues, and opportunities for practitioner development. Consulting Psychology Journal: Practice and Research, 68(2), 143-156.

Bachkirova, T., Jackson, P., \& Clutterbuck, D. (2011). Coaching and mentoring Supervision: The complete guide to best practice. Berkshire, England: McGraw-Hill Open University Press. 
Baer, R. A., Smith, G. T., Hopkins, J., Krietemeyer, J., \& Toney, L. (2006). Using self-report assessment methods to explore facets of mindfulness. Assessment, 13(1), 27-45.

Bandura, A. (2005). The primacy of self-regulation in health promotion. Applied Psychology, 54(2), 245-254.

Baron, L., \& Morin, L. (2009). The coach-coachee relationship in executive coaching: A field study. Human Resource Development Quarterly, 20(1), 85-106.

Bar-On, R. (1997). Technical manual for the emotional quotient inventory. Toronto, Canada: Multi-Health Systems.

Bennett, J. L., \& Rogers, K. D. B. (2011). Skill acquisition of executive coaches: A journey toward mastery. Charlotte, NC: McColl School of Business, Queens University of Charlotte.

Blumberg, K. M. (2014). Executive coaching competencies: a review and critique with implications for coach education. Journal of Psychological Issues in Organizational Culture, 5(2), 87-97.

Boud, D., Keogh, R., \& Walker, D. (1985). Promoting reflection in learning: A model. In D. Boud, R. Keogh, \& D. Walker (Eds.) Reflection: Turning experience into learning (pp. 18-40). London: Kogan Page.

Boyatzis, R. E. (2006). An overview of intentional change from a complexity perspective. Journal of Management Development, 25(7), 607-623.

Boyatzis, R. E., Smith, M. L., Van Oosten, E., \& Woolford, L. (2013). Developing resonant leaders through emotional intelligence, vision and coaching. Organizational Dynamics, 42(1), 17-24.

Branson, C. M. (2007). Improving leadership by nurturing moral consciousness through structured self-reflection. Journal of Educational Administration, 45(4), 471-495.

Bratton, V. K., Dodd, N. G., \& Brown, F. W. (2011). The impact of emotional intelligence on accuracy of self-awareness and leadership performance. Leadership \& Organization Development Journal, 32(2), 127-149.

Brown, K. W., Ryan, R. M., \& Creswell, J. D. (2007). Mindfulness: Theoretical foundations and evidence for its salutary effects. Psychological Inquiry, 18(4), 211-237.

Carlson, E. N. (2016). Meta-accuracy and relationship quality: Weighing the costs and benefits of knowing what people really think about you. Journal of Personality and Social Psychology, 111(2), 250-264.

Carroll, M. (2010). Supervision: Critical reflection for transformational learning (Part 2). The Clinical Supervisor, 29(1), 1-19.

Chambers, R., Gullone, E., \& Allen, N. B. (2009). Mindful emotion regulation: An integrative review. Clinical Psychology Review, 29(6), 560-572. 
Church, A. H. (1997). Managerial self-awareness in high-performing individuals in organizations. Journal of Applied Psychology, 82(2), 281292.

Corno, L., \& Kanfer, R. (1993). The role of volition in learning and performance. Review of Research in Education, 19(1), 301-341.

Cox, E. (2015). Coaching and adult learning: Theory and practice. In J. Pappas and J. Jerman (Eds.), New Directions for Adult and Continuing Education, 2015 (148) (pp. 27-38). San Francisco, CA: Jossey-Bass.

Cox, E., Bachkirova, T., \& Clutterbuck, D. A. (Eds.). (2014). The complete handbook of coaching. Thousand Oaks, CA: Sage Publishing.

de Haan, E., Duckworth, A., Birch, D., \& Jones, C. (2013). Executive coaching outcome research: The contribution of common factors such as relationship, personality match, and self-efficacy. Consulting Psychology Journal: Practice and Research, 65(1), 40-57.

Dewey, J. (1997). How we think: A restatement of the relation of reflective thinking to the educative process. Boston, MA: D.C. Heath \& Co Publishers. (Original work published 1933)

Duval, S., \& Wicklund, R. A. (1972). A theory of objective self-awareness. Oxford, England: Academic Press.

Eurich, T. (2017). Insight: Why we're not as self-aware as we think, and how selling ourselves clearly helps us succeed at work and in life. New York, NY: Crown Business.

European Mentoring and Coaching Council (EMCC). (2015). EMCC competence framework $v 2$. Retrieved October 5, 2019 from https://emcc1.app.box.com/s/4aj8x6tmbt75ndn13sg3dauk8n6wxfxq

Fenigstein, A. (1987), On the nature of public and private self-consciousness. Journal of Personality, 55, 543-554.

Fenigstein, A., Scheier, M. F., \& Buss, A. H. (1975). Public and private selfconsciousness: Assessment and theory. Journal of Consulting and Clinical Psychology, 43(4), 522-527.

Fiske, S. T., \& Taylor, S. E. (2013). Social cognition: From brains to culture. Thousand Oaks, CA: Sage.

Fogel, A. (2009). The Norton series on interpersonal neurobiology. The psychophysiology of self-awareness: Rediscovering the lost art of body sense. New York, NY: W W Norton \& Co.

Freire, P. (1970). Pedagogy of the oppressed (M. B. Ramos, Trans.). New York, NY: The Continuum International Publishing Group Inc.

Gan, G., \& Chong, C. (2015). Coaching relationship in executive coaching: A Malaysian study. Journal of Management Development, 34(4), 476-493. 
Gard, T., Noggle, J. J., Park, C. L., Vago, D. R., \& Wilson, A. (2014). Potential self-regulatory mechanisms of yoga for psychological health. Frontiers in human neuroscience, 8, 770.

Gatling, A. R., Castelli, P. A., \& Cole, M. L. (2013). Authentic Leadership: The role of self-awareness in promoting Coaching effectiveness. AsiaPacific Journal of Management Research and Innovation, 9(4), 337347.

Gibbs, G. (1988). Learning by doing: A guide to teaching and learning methods. London, UK: Further Education Unit.

Goleman, D. (1995). Emotional intelligence. New York, NY: Bantam Books.

Grant, A. M. (2003). The impact of life coaching on goal attainment, metacognition and mental health. Social Behavior and Personality: An International Journal, 31(3), 253-263.

Grant, A. M. (2012). An integrated model of goal-focused coaching: An evidence-based framework for teaching and practice. International Coaching Psychology Review, 7(2), 146-165.

Grant, A. M., Franklin, J., \& Langford, P. (2002). The self-reflection and insight scale: A new measure of private self-consciousness. Social Behavior and Personality: An International Journal, 30(8), 821-835.

Gratz, K. L., \& Roemer, L. (2004). Multidimensional assessment of emotion regulation and dysregulation: Development, factor structure, and initial validation of the difficulties in emotion regulation scale. Journal of Psychopathology and Behavioral Assessment, 26(1), 41-54.

Gray, D. E. (2007). Facilitating management learning: Developing critical reflection through reflective tools. Management Learning, 38(5), 495517.

Green, J., \& Grant, A. M. (2003). Solution-focused coaching: Managing people in a complex world. London, UK: Pearson Education.

Green, L. S., Oades, L. G., \& Grant, A. M. (2006). Cognitive-behavioral, solution-focused life coaching: Enhancing goal striving, well-being, and hope. The Journal of Positive Psychology, 1(3), 142-149.

Gross, J. J. (2014). Emotion regulation: Conceptual and empirical foundations. In J. J. Gross (Ed.), Handbook of emotion regulation (pp. 3-20). New York, NY: Guilford Press.

Grossman, P., Niemann, L., Schmidt, S., \& Walach, H. (2004). Mindfulnessbased stress reduction and health benefits: A meta-analysis. Journal of Psychosomatic Research, 57(1), 35-43.

Guiffrida, D. (2015). A constructive approach to counseling and psychotherapy supervision. Journal of Constructivist Psychology, 28(1), 40-52. 
Habermas, J. (1984) The theory of communicative action, Vol. 1 Reason and the rationalization of society. Boston, MA: Beacon Press.

Hall, D. T. (2004). Self-awareness, identity, and leader development. In D. V. Day, S. J. Zaccaro, \& S. M. Halpin (Eds.), Leader Development for Transforming Organizations: Growing Leaders for Tomorrow (pp. 153176). Hillsdale, NJ: Lawrence Erlbaum Associates.

Hall, P. A., \& Fong, G. T. (2007). Temporal self-regulation theory: A model for individual health behavior. Health Psychology Review, 1(1), 6-52.

Hargrove, R. A. (1995). Masterful coaching: Extraordinary results by impacting people and the way they think and work together. San Diego, CA: Pfeiffer \& Company.

Harvey, J. B. (2015). Coaching from essence: Potential \& vulnerability drive professional mastery. Choice, 13(2).

Hawkins, P. (2014). Coaching supervision. In E. Cox, T. Bachkirova, \& D. A. Clutterbuck, (Eds.). (pp. 391-404). The complete handbook of coaching. Thousand Oaks, CA: Sage Publishing.

Hodge, A. A. (2016). The value of coaching supervision as a development process: Contribution to continued professional and personal wellbeing for executive coaches. International Journal of Evidence Based Coaching \& Mentoring, 14(2), 87-106.

Humphrey, R. H., \& O’Boyle, E., Jr., Pollack, J. M., Hawver, T. H., \& Story, P. A. (2011). The relation between emotional intelligence and job performance: A Meta-analysis. Journal of Industrial and Organizational Psychology, 32(5), 788-818.

International Coach Federation (ICF). (n.d.). Core Competencies. Retrieved October 5, 2019 from https://coachfederation.org/core-competencies

Jones, R. J., Woods, S. A., \& Guillaume, Y. R. F. (2016). The effectiveness of workplace coaching: A meta-analysis of learning and performance outcomes from coaching. Journal of Occupational and Organizational Psychology, 89(2), 249-277.

Kegan, R., \& Lahey, L. L. (2009). Immunity to Change. Boston, MA: Harvard Business Press.

Kemp, T. (2016). Mindfulness and coaching: Contemporary labels for timeless practices. In T. Bachikirova, G. Spence, \& D. Drake (Eds.), The SAGE Handbook of Coaching, (pp. 381-398). London, UK: Sage.

Kilburg, R. R. (2000). Executive coaching: Developing managerial wisdom in a world of chaos Washington, DC: American Psychological Association.

Kolb, D. A. (1984). Experiential learning: Experience as the source of learning and development. Englewood Cliffs, NJ: Prentice-Hall. 
Kolb, D. A., \& Boyatzis, R. E. (1971). Goal-setting and self-directed behavior change. In D. A. Kolb, I. M. Rubin, \& J. M. McIntyre (Eds.), Organizational psychology: A book of readings (pp. 317-337). Englewood Cliffs, NJ: Prentice-Hall.

Kuhl, J., \& Fuhrmann, A. (1998). Decomposing self-regulation and selfcontrol: The volitional components inventory. In J. Heckhausen \& C. S. Dweck (Eds.), Motivation and self-regulation across the life span (pp. 15-49). New York, NY, US: Cambridge University Press.

Langer, E. J. (1989). Mindfulness. Reading, MA: Addison-Wesley.

Langer, E. J. (2014). Mindfulness in the Age of Complexity. Harvard Business Review, 92(3), 68-73.

Latham, G. P., \& Locke, E. A. (1991). Self-regulation through goal setting. Organizational Behavior and Human Decision Processes, 50(2), 212247.

Lawrence, P., \& Whyte, A. (2014). What is coaching supervision and is it important? Coaching: An International Journal of Theory, Research and Practice, 7(1), 39-55.

Locke, E. A., \& Latham, G. P. (1990). A theory of goal setting \& task performance. Englewood Cliffs, N.J.: Prentice-Hall.

Mamede, S., \& Schmidt, H. G. (2004). The structure of reflective practice in medicine. Medical Education, 38(12), 1302-1308.

Mann, K., Gordon, J., \& MacLeod, A. (2009). Reflection and reflective practice in health professions education: a systematic review. Advances in Health Sciences Education, 14(4), 595-621.

Markus, H., \& Wurf, E. (1987). The dynamic self-concept: A social psychological perspective. Annual Review of Psychology, 38(1), 299337.

Mayer, J., \& Salovey, P. (1993). The intelligence of emotional intelligence. Intelligence, 17(4), 433-442.

McGivern, L. (2009). Continuous professional development and avoiding the vanity trap: An exploration of coaches' lived experiences of supervision. International Journal of Evidence Based Coaching and Mentoring, Special Issue No. 3, 22-37.

McKenna, D. D., \& Davis, S. L. (2009). Hidden in plain sight: The active ingredients of executive coaching. Industrial and Organizational Psychology: Perspectives on Science and Practice, 2, 244-260.

Merriam, S. B. (2011). Third Update on Adult Learning Theory: New Directions for Adult and Continuing Education, Number 119 (94). Hoboken, NJ: John Wiley \& Sons. 
Mezirow, J. (1990). Fostering critical reflection in adulthood: A guide to transformative and emancipatory learning. San Francisco, CA: JosseyBass.

Mischel, W., \& Ebbesen, E. B. (1970). Attention in delay of gratification. Journal of Personality and Social Psychology, 16(2), 329337.

Moon, J. A. (2013). Reflection in learning and professional development: Theory and practice. London, UK: Routledge.

National Institutes of Health. (2017). Meditation: In depth. Retrieved from https://nccih.nih.gov/health/meditation/overview.htm.

O'Donoghue, T., \& Rabin, M. (2003). Self-awareness and self-control. In G. Loewenstein, D. Read, \& R. Baumeister (Eds.), Time and decision: Economic and psychological perspectives on intertemporal choice (pp. 217-243). New York, NY: Russell Sage Foundation.

Oaten, M., \& Cheng, K. (2006). Longitudinal gains in self-regulation from regular physical exercise. British Journal of Health Psychology, 11(4), 717-733.

Osterman, K. F., \& Kottkamp, R. B. (2004). Reflective practice for educators: Professional development to improve student learning. Thousand Oaks, CA: Corwin Press.

Passmore, J. (Ed.). (2015). Excellence in coaching: The industry guide. Philadelphia, PA: Kogan Page Publishers.

Passmore, J., McMahon, G., Brennan, D., Lee, B., Christian, B., \& Tenzyk, M. (2011). Using case studies for reflective practice. In J. Passmore (Ed.), Supervision in Coaching: Supervision, Ethics, and Continuous Professional Development (pp. 309-327). Philadelphia, PA: Kogan Page Limited.

Perrig, W. J., \& Grob, A. (Eds.). (2000). Control of human behavior, mental processes, and consciousness: essays in honor of the 60th birthday of August Flammer. Mahwah, NJ: Lawrence Erlbaum Associates, Inc.

Pinkavova, E. (2010). Keeping our heads above water: applying Kegan's' orders of consciousness' theory in coaching. International Journal of Evidence Based Coaching \& Mentoring, 8(1), 14-21.

Pintrich, P. R. (2000). The role of goal orientation in self-regulated learning. In M. Boekaerts, P. Pintrich, \& M. Zeidner (Eds.) Handbook of selfregulation (pp. 451-502). Cambridge, MA: Academic Press.

Richards, K., Campenni, C., \& Muse-Burke J. (2010). Self-care and well-being in mental health professionals: The mediating effects of self-awareness and mindfulness. Journal of Mental Health Counseling, 32(3), 247-264. 
Rogers, J. (2012). Coaching skills: A handbook(3rd ed.). Berkshire, England: Open University Press.

Rotter, J. B. (1966). Generalized expectancies for internal versus external control of reinforcement. Psychological Monographs: General and Applied, 80(1), 1-28.

Salazar, W. (2018). The benefits of meditation for stress relief. GoodTherapy.org. Retrieved from https://www.goodtherapy.org/blog/benefits-of-meditation-for-stressrelief-0220185?utm_source=Subscribers\&utm_campaign $=44590 \mathrm{a} 3 \mathrm{a} 3 \mathrm{c}-$ EMAIL_CAMPAIGN_2018_02_20\&utm_medium=email\&utm_term= $0 \_1359 \overline{4} 6 \mathrm{a} 8 \mathrm{dd}-44590 \overline{\mathrm{a}} \mathrm{3} \mathrm{a} 3 \mathrm{c}-\overline{7} 22 \overline{4} 2693$

Salovey, P., \& Mayer, J. D. (1990). Emotional intelligence. Imagination, Cognition and Personality, 9(3), 185-211.

Schön, D. A. (1983). The reflective practitioner: How professionals think in action. New York, NY: Basic Books.

Schunk, D. H., \& Zimmerman, B. (Eds.). (2011). Handbook of self-regulation of learning and performance. Milton Park, UK: Taylor \& Francis.

Silvia, P. J. \& O'Brien, M. E. (2004). Self-awareness and constructive functioning: Revisiting "the human dilemma." Journal of Social and Clinical Psychology, 23(4), 475-489.

Skinner, B. F. (1974). About behaviorism. New York: Alfred A. Knopf.

Sonesh, S. C., Coultas, C. W., Marlow, S. L., Lacerenza, C. N., Reyes, D., \& Salas, E. (2015). Coaching in the wild: Identifying factors that lead to success. Consulting Psychology Journal: Practice and Research, 67(3), 189-217.

Spence, G. B. (2007). Further development of evidence-based coaching: Lessons from the rise and fall of the human potential movement. Australian Psychologist, 42(4), 255-265.

Stacey, R. D., \& Griffin, D. (2006). A complexity perspective on researching organizations: Taking experience seriously. Milton Park, UK: Routledge.

Stober, D. R., \& Grant, A. M. (Eds.). (2010). Evidence based coaching handbook: Putting best practices to work for your clients. Hoboken, NJ: John Wiley \& Sons.

Sutton, A. (2016). Measuring the effects of self-awareness: construction of the self-awareness outcomes questionnaire. Europe's Journal of Psychology, 12(4), 645-658.

Sutton, A., Williams, H. M., \& Allinson, C. W. (2015) A longitudinal, mixed method evaluation of self-awareness training in the workplace. European Journal of Training and Development, 39(7), 610-627. 
Tekleab, A. G., Sims, H. P., Jr., Yun, S., Tesluk, P. E., \& Cox, J. (2008). Are we on the same page? Effects of self-awareness of empowering and transformational leadership. Journal of Leadership and Organizational Studies, 14(3), 185-201.

Theeboom, T., Beersma, B., \& van Vianen, A. E. M. (2014). Does coaching work? A meta-analysis on the effects of coaching on individual level outcomes in an organizational context. The Journal of Positive Psychology, 9(1), 1-18.

Thompson, N. (2015). People skills. Basingstoke, UK: Palgrave Macmillan.

Thompson, R. A. (1994). Emotion regulation: A theme in search of definition. Monographs of the Society for Research in Child Development, 59(2-3), 25-52.

Trapnell, P. D., \& Campbell, J. D. (1999). Private self-consciousness and the five-factor model of personality: Distinguishing rumination from reflection. Journal of Personality and Social Psychology, 76(2), 284304.

Vago, D. R., \& Silbersweig, D. A. (2012). Self-awareness, self-regulation, and self-transcendence (S-ART): A framework for understanding the neurobiological mechanisms of mindfulness. Frontiers in Human Neuroscience, 6, 296.

Vandaveer, V. V., Lowman, R. L., Pearlman, K., \& Brannick, J. P. (2016). A practice analysis of coaching psychology: Toward a foundational competency model. Consulting Psychology Journal: Practice and Research, 68(2), 118-142.

Vohs, K. D., \& Baumeister, R. F. (2016). Handbook of self-regulation: Research, theory, and applications. New York, NY: Guilford Publications.

Waugh, C. E., Thompson, R. J., \& Gotlib, I. H. (2011). Flexible emotional responsiveness in trait resilience. Emotion, 11(5), 1059-1067.

Wilber, K. (2000). Integral psychology: Consciousness, spirit, psychology, therapy. Boston, MA: Shambhala Publications.

Woods, D. (2011). Coaches' use of reflective journals for learning. In J. Passmore (Ed.), Supervision in coaching: Supervision, ethics, and continuous professional development (pp. 265-284). Philadelphia, PA: Kogan Page Limited.

Zes, D. \& Landis, D. (2013). A better return on self-awareness. Retrieved from https://www.kornferry.com/institute/better-return-self-awareness.

Zimmerman, B. J. (2000). Attaining self-regulation: A social cognitive perspective. In M. Boekaerts, P. Pintrich, \& M. Zeidner 
(Eds.) Handbook of self-regulation (pp. 13-39). Cambridge, MA: Academic Press. 


\title{
What is Systemic Coaching?
}

\author{
Paul Lawrence \\ Sydney, Australia
}

\begin{abstract}
The term 'systemic coaching' is now widely used, usually to articulate the value for the coach of looking beyond the immediacy of the one-to-one coaching relationship. It is also being used to describe some specific, and quite different, ways of thinking about systems. If coaches are to make sense of this evolving narrative, and to clarify their own individual perspectives, then the industry as a whole must further familiarise itself with relevant thinking from the worlds of management science and organisational development. A necessarily high-level overview of systems theory is presented in this paper, together with illustrations as to how a systemic coaching philosophy might manifest differently when grounded in different ways of thinking about systems. First and second-order systems theories, complexity theories, and theories of complex responsive processes are outlined, ultimately with the objective of enabling coaches to make their own sense of self-as-systemic-coach.
\end{abstract}

Keywords: coaching, systemic coaching, systems thinking, systemic, systematic

\section{Introduction}

The term 'systemic coaching' is becoming increasingly popular, the term often used as if it represents a single philosophy. The relatively recent emergence of the term has accompanied a new level of reflection on the complexity of the world today. As Hofkirchner and Rousseau (2015) put it:

The crises we face are systemic in nature. To overcome those crises we need to understand how systems work. To arrive at such an understanding we need to think systemically.

Whilst becoming more popular, the term 'systemic coaching' is used to represent different approaches to coaching, often without a detailed explanation of how the term is being used, the philosophical underpinnings of the particular definition, or a comparison to other uses of the term. There is a risk that the term 'systemic coaching' becomes appropriated by a plethora of practitioners, some of whom using the term to describe approaches that lack substance or

This is an Open Access article distributed under the terms of the Creative Commons Attribution (CC BY) License which permits use, distribution and reproduction in any medium, provided the original work is properly cited. 
grounding. Indeed, systemic coaching may become the new neuro-leadership, an example of "pop-science band-wagoning" (Grant, 2015). The purpose of this paper is not to critique existing narratives. Instead the aim is to lay out at a necessarily high level the development of thinking in the systems thinking domain, in particular how it has been interpreted by the organisational development community and others working in the management sciences. This is a specific field of enquiry that has been active for more than 60 years but has yet to be fully embraced by the coaching community. It is the purpose of this paper to layout some key themes in the area of system thinking, not in service of commending a particular approach or philosophy, but to stimulate further dialogue as to how theories of systems thinking may be most usefully applied in the coaching domain and to begin to illustrate how different systems philosophies may manifest differently in practice.

The coaching community is not the first to encounter the challenge of making visible the similarities and differences between different uses of the term 'systemic'. Lane and Jackson (1995) said of the systems thinking community generally:
Using the term 'systems thinking' in a way which is both imprecise and, apparently, unaware of intellectual antecedents also has the effect of blurring the boundaries between different approaches." And the “... usage of the term 'systems thinking' is spreading in the SD (systems dynamics) community with an enthusiasm which verges on the hegemonic. The employment of this term to describe our own single methodology is virtually to deny the existence of any other, if we use that term for our own discipline, we are putting ourselves in a mental prison.

In this paper a high-level overview of systems theory is presented, followed by some specific examples to illustrate how the same term may be used to describe quite different approaches to coaching. Key points of difference between these approaches are then identified which, it is hoped, will enable both effective comparison both between and within different philosophies, and a critique of methodologies claiming to represent established schools of thought.

Three uses of the term 'systemic' are cited here in order to illustrate how idiosyncratic the phrase 'systemic coaching' may become. None of these three usages is being criticised (indeed one is the author's own), rather the three approaches are detailed to illustrate how different they are from each other. First, Whittington (2012) defines systemic coaching as "that which acknowledges, illuminates and releases the system dynamics so that each 
element can function with ease." Systems dynamics are defined as the outcome of interactions between forces that exist between parts in a system, a system being defined as a set of interacting or interdependent entities forming a whole. The purpose of systemic coaching is to identify the 'truth' of the system and to restore 'system coherence' so that people in the system understand their place and are free to operate at their best. Whittington's book focuses on the application of a particular technique, called constellations work. A constellation is defined as a practical intervention, the objective of which is to illuminate invisible dynamics behind relationship difficulties, stuck issues and challenges. The creation of a constellation enables participants to identify patterns and dynamics in service of resolving issues.

As will become clear, this appears to be an example of first-order systems thinking. Clutterbuck (2007) contrasts 'thinking systematically' with 'thinking systemically'. To think systemically is to take a holistic approach that recognises the organisation to be a complex entity, comprising interconnected parts. It is a way of thinking that helps coach and coachee avoid engaging in over-simplistic analyses and coming up with over-simplistic solutions. Clutterbuck's perspective is defined in less detail than is Whittington's, but appears to eschew aspects of first-order thinking and commend an approach based on second-order systems thinking or complexity theory. Lawrence (2015) suggests that systemic coaching is not about a particular set of skills or techniques, rather it is a mindset, that includes a belief in the significance of 'authentic reflective dialogue'. Dialogue is defined with reference to the work of Bohm (1996) and Isaacs (1999), and the author makes explicit reference to Stacey's notion of 'complex responsive processes' and to his rejection of the idea that practitioners can successfully stand outside an organisation system and diagnose it as if it were a system (Stacey, 2012; Stacey \& Mowles, 2016).

These three perspectives on systemic thinking are quite different, but identifying where they are different and where they similar is not straightforward without reference to a broader perspective on systems thinking. Consequently, it is likely that practitioners, and others in the industry, may be becoming increasingly confused as to what the word 'systemic' means in the context of coaching.

\section{Systems theories}

A spate of papers on systems thinking were published in the 1950 s, by biologists, economists and engineers (Stacey \& Mowles, 2016). Three strands of thinking; general systems theory, cybernetic systems and systems dynamics 
co-evolved, and these ideas and philosophies began to permeate other disciplines, including management theory. From these three schools of thought emerged other ideas, including Living Systems Theory (Miller, 1978; Bailey, 2005), autopoiesis (Varela, Maturana \& Uribe, 1974), Soft Systems Methodology (Checkland, 1994, 2000, 2012; Checkland \& Haynes, 1994), Critical Systems Thinking (Ulrich, 2003), chaos theory (Gleick, 1988), complexity theory (Gell Mann, 1994), Complex Adaptive Systems (Marion \& Uhl-Bien, 2001) and within each of these theories there exist significant variations on a theme. Space does not permit a thorough articulation of each of these theories. Instead four theories will be presented in service of isolating key points of difference, an understanding of which may help coaches identify their own particular philosophy as to what it means to be a systemic coach, and to question and challenge others who talk about being systemic. These four theories will be loosely referenced to a typology borrowed from Stacey and Mowles (2016).

\section{First-order systems theories}

Ludwig von Bertalanffy (1969) was an Austrian biologist who developed a general systems theory in response to the inadequacy of purely mechanistic theories to address theoretical problems, particularly in the biosocial sciences. He noted that whilst the physicist, the biologist, psychologist and social scientists were focused on their own areas of study, they seemed to be working on similar problems. General Systems Theory (GST) is an attempt to identify universal principles that apply across different fields of study (Amerikaner, 1981; Caws, 2015; Malecic, 2017; Rousseau, 2015; Schneider \& Somers, 2006). A major contribution of GST was to switch attention to the functioning of open systems. Physical chemistry, up until that time, had tended to focus on closed systems, operating in isolation of their surrounding environments. Some first-order systems, for example first-order cybernetics, also modelled closed systems (Bateson, 1967; Guy, 2018; Lepskiy, 2018; Schwaniger, 2015; Scott, 2016; Stacey \& Mowles, 2016). Open systems, by contrast, maintain themselves through a continuous exchange of components in and out of the system, across boundaries. These systems are self-regulating, with equilibrium maintained by forces acting to dampen the effect of disturbance from outside. Whilst Bertalanffy believed that social systems were subject to these same systemic principles as other systems, he recognised that they were very complicated, such that the system could only be understood in terms of general principles. He sought to model the activity of open systems through the use of mathematical models, on the basis that statistical averages could adequately represent the activity of 'incalculable unknown processes'. GST, Bertalanffy 
said, is a 'logico-mathematical science of wholeness', seeking to develop future insights through the application of mathematics.

From this brief description of GST we can identify three underlying assumptions that will serve to contrast first-order systems thinking from other schools of thought. First, it is assumed that a social system is a real system, like a machine, or a living organism. Second, it is assumed that the operation of a first-order system is ultimately logical and can be modelled mathematically. Third, it is assumed that the external observer can stand outside the system, diagnose its functioning, and design interventions that will control its future operation.

\section{First-order systems thinking in the coach}

A coach operating to first-order principles is likely to regard organisational systems as real, and to think in terms of boundaried sub-systems. The coach is unlikely to look often beyond linear cause-and-effect and will search out such relationships when presenting scenarios appear complicated. Consistent with first-order cybernetic principles, change will be regarded as the exception to the norm, and the purpose of coaching may be to move or return to a predictable form of equilibrium. The coach may tend to talk about the organisation as if coach and coachee can usefully position themselves outside the system, in service of coming up with interventions designed to shift the functioning of the system at a macro-level. Watching such a coach in action we might see the coach encouraging the coachee to collect data and information in service of creating a full and comprehensive understanding of the way the organization works. Conversation is likely to focus on enhancing or upgrading component parts of the system in the belief that the performance of the system as a whole will inevitably improve if the quality of the parts is upgraded. This is analogous to organisation-as-machine; if my car will not start then I must identify which part of the engine needs to be mended or replaced. In an organisational setting this might mean motivating particular individuals or otherwise focusing on individual performance. Feedback is therefore important in enabling individuals to perform more effectively. Coach and coachee may come up with medium/long term coaching plans or seek to address strategic uncertainty in the business again by means of medium/long term planning.

\section{Second-order systems theories}

With reference to GST, Checkland (2000) believes that attempts to identify general rules, that may be mathematically modelled and applied to all 
systems, have failed. They have failed because the world is seen to be too "complex, problematical and mysterious". The first two assumptions underlying first-order systems thinking are therefore challenged, namely the assumptions that a social system is usefully regarded as a real system, and second that the operation of a social system can be modelled mathematically. Gregory Bateson expressed a similar view in suggesting that people can never perceive reality directly, that they perceive only a personal representation of reality (Hawkins, 2004; Kobayashi, 1988). The organisation as system can thus only usefully be regarded as a metaphor, and it must be acknowledged that different people will conjure up different metaphors based on their individual perception of the organisation. Instead of thinking of the world as a set of systems therefore, it is better to construct a systemic process of inquiry (Atkinson \& Checkland, 1988; Checkland, 1994, 2000, 2012; Checkland \& Haynes, 1994). In other words, in first-order thinking systemicity is assumed to be in the world, whereas through the lens of Soft Systems Methodology (SSM) systemicity is assumed to be an aspect of process through which we engage with the world.

Stacey (2012) critiques the evolution of his own systems thinking and regrets the popularity of one of his models. He refers to the second edition of 'Strategic Management and Organisational Dynamics' in which he presented a chart with two axes, charting levels of certainty against level of agreement between people. High levels of certainty and agreement indicated stability and predictability, which validated the use of standard management tools. Low levels of certainty and agreement represented anarchy and necessitated alternative approaches. The model is quite similar to the well-known Cynefin model (Snowden \& Boone, 2007). Both models invite the outside observer to diagnose the system and determine the nature of an effective intervention. The problem with both models from a second-order perspective, is that they imply that an individual is able to stand outside the system and make an objective assessment of what is happening in the system.

The development of SSM was marked by three key ideas (Atkinson \& Checkland, 1988; Checkland, 1994, 2000, 2012; Checkland \& Haynes, 1994). These are:

- All problems are situations in which people are trying to take purposeful action.

- Different people have different perspectives on a situation, and therefore different versions of what needs to happen next. 
- Therefore, people need to work together to come up with a working model of the system, in service of coming up with a plan of action, and they need to learn together from the application of the model.

SSM is built upon these three key ideas. Application of an SSM entails i) a consideration of a real-world problem ii) the formulation of models to depict the problem in the form of systems iii) an inquiry of the problem using the model as a source of questions iv) the identification of actions.

The main difference then between first and second order systems thinking, working with social systems, is the extent to which it is appropriate to regard the social system as a real system. What both approaches have in common is the idea that the leader or coach is able to stand outside the system, alone or with others, and conduct some form of diagnosis in service of coming up with the solution to a problem.

\section{Second-order systems thinking in the coach}

A second-order systemic coach is unlikely to regard the coachee's perspective on an issue as a single truth. The coach will be curious as to what other people in the system are thinking, and through what lenses they are observing events. The coach will encourage the coachee to engage with others, to seek out different perspectives and to integrate those perspectives in seeking to further understand events. Because the coach regards the organisation as 'complex, problematical and mysterious', the coach will encourage the coachee to experiment and to reflect on the outcomes of actions taken. Such coaches are, moreover, conscious of the subjectivity of their own perspectives. They seek to enhance those perspectives through collaborative reflective practice. Watching such a coach in action we may see the coach encouraging coachees to explore their own mental models, and the mental models of others in organisation. The coach is likely to hold their own hypothesis as to how the organisation is operating 'lightly', and encourages the coachee to do the same.

\section{Complexity theories}

There are a multitude of different complexity theories. Complex Adaptive Systems (CAS) theory is one form of complexity theory, and there are multiple interpretations of CAS (Gell Mann, 1994; Schneider \& Somers, 2006). Many complexity theories are not fundamentally dissimilar from first and/or second order systems thinking, in that they appear to assume that an organisation may be regarded as a real system and/or that the organisation as system can be diagnosed and understood and interventions plotted from outside. Stacey and 
Mowles (2016) suggest that chaos theory and theories of dissipative structures, both complexity theories, are similar to first and second order systems thinking in that they focus on the macro and offer little insight as to the detailed mechanics underlying organisational function, a focus on the micro that is fundamental to other complexity theories.

Where both theories are useful, he suggests, is in introducing the notion of stable instability, or unstable stability. Mathematicians found that systems dynamics models produced wholly predictable patterns within certain parameters. These patterns are referred to as 'attractors'. Within other parameters the system becomes disorganised. In between stability and disorganisation is a pattern that looks random, but on closer examination is not. This pattern is called a 'strange attractor' or 'fractal'. This is a dynamic in which stability and instability are both present. The pattern is apparently chaotic, but the apparent chaos belies a state of order, it is just that the pattern of activity is highly unusual. These mathematical models have been used to explain weather systems, a good example of stable instability. We may complain how unpredictable is the weather, but we know it never snows on Bondi Beach or in the Sahara Desert. In other words, whilst someone living in Sydney may not know whether it is going to rain tomorrow (unpredictable), they do know they will not be building snowmen (predictable). This idea of predictable unpredictability takes systemic thinking to another place, away from a preoccupation with equilibrium to a consideration of the necessary conditions for change. Applying these theories to organisations is to advocate a movement toward 'chaos', because it is only in this state of stable instability that change happens, and most organisations want to achieve some sort of change.

Though there exist multiple perspectives of CAS, most theories align around common principles (e.g. Boal \& Schultz, 2007; Cavanagh, 2006; Kamo $\&$ Phillips, 1997). The focus is on the micro rather than the macro. Instead of assuming that agents in a system are passive, or that we can somehow assume an average level of activity, agents in a complex adaptive system are assumed to be operating to local rules. Local agents interact with each other and with their environment and from those interactions emerge aggregate behaviours. Local sub-systems are then subject to feedback from these aggregated behaviours and respond to it. Interaction at the local level continues to evolve as local agents seek to survive in the environment provided by all the parts of the system, and local rules emerge anticipating responses to the wider environment. 
Some writers have illustrated these principles with reference to the flocking of birds. Each bird may be operating according to a rule that says, for example, fly alongside and slightly behind one of your fellow birds, and if there are already twenty birds in line, drop back and fly behind a fellow bird etc. There is no overall blue-print and the birds are not attempting to fly in formation. The shape of the flock is an outcome of the behaviour of individuals, each adhering to a simple rule. The flocking of birds illustrates a basic principle of CAS but is not a good metaphor for the functioning of CAS in an organisational setting, because in an organisation each individual or sub-system is likely to be operating to its own specific and dynamic set of rules. In other words, what flying pattern would emerge if each bird, or small group of birds, was operating to a different simple rule, a rule which shifted and changed? The emerging pattern would be both unpredictable and dynamic.

This perspective on a system renders absurd the notion of the external practitioner standing outside the system, plotting its future trajectory. For even if the diagnosis is conducted by a group of people, all recognising the limitations of their own perspectives and working in collaboration, this group is but one sub-system in the whole, and there will be other individuals and groups having similar and yet different conversations. Each group will encounter other groups in its local vicinity, and from those interactions will emerge something unpredictable.

\section{Complexity thinking in the coach}

The coach believes it is important to look beyond the behaviour of the individual in order to understand events. The coach is curious as to the nature of local interactions, and the convergence of different schools of thought across the organisational system. The coach will be interested, above all, in seeking to understand interpersonal dynamics, and will take advantage of any opportunity to personally witness social interactions. The coach searches for tensions in the system, recognising that change tends to emerge in conditions of ambiguity and uncertainty. The coach may express little interest in drawing detailed plans, believing that change tends to emerge and that efforts to direct change in a particular direction over a period of time ae unlikely to succeed. Watching such a coach in practice, we might observe the coach encouraging the coachee to challenge the mindset that suggests leaders can control outcomes. The coach will focus above all on social interaction, and the nature of that interaction, and on the emergence and evolution of social identity and power dynamics. The coach is fully aware that their own behaviour and utterances are as much a part of the system as any other agent in the organisational environment. The coach's 
behaviour will be informed by that understanding and by an ongoing attunement to changes in the environment.

\section{Complex responsive processing}

There are many different versions of complexity thinking, most focusing on the behaviour of individual agents, or sub-systems. To further their understanding of complex systems, mathematical modelers assign rules to individual agents and observe the outcome of the interaction between those agents. But how applicable is this approach in seeking to understand the behaviour of social systems, where the individual unit is a human being or a collective of human beings? Human beings are not flocking birds, all acting in accordance with standard simple rules. Human beings are conscious, emotional and spontaneous, capable themselves of observing the pattern of interactions within which they are operating and responding accordingly. People think about their work, are often bored by repetition, seek novelty, dislike being told what to do, and may seek to avoid change (Suchman, 2011). In this sense human beings, and the interactions between human beings, may be un-modellable, and the system metaphor may not actually be very useful (Bovaird, 2008; Stacey \& Mowles, 2016; Suchman, 2011).

Stacey and Mowles (2016) suggest it is most useful to focus on the responsive manner in which humans interact with each other, an approach they label 'complex responsive processing'. Through this lens no-one can control the functioning of the whole. The role of the leader is to engage intentionally and skillfully in local interaction, responding in the moment to events as they emerge. Whilst we can still talk about the functioning of human systems, ideas from systems thinking that imply some level of logical or rational relationship between entities, may not work for the student of social systems in the same way they may work better for the student of physics or engineering. The systems metaphor in this case may be less useful than confusing, in terms of implying the possibility of objective diagnosis and management control. Stacey's thinking on complex responsive processes is very much influenced by the work of the sociologist Norbert Elias. Elias argued that the notion of society as a whole, serves as an interesting abstraction but does not reflect the dynamic nature of human social life, with all its contradiction, tension, and unpredictable localised interaction. Social order in this sense, is not a stable equilibrium to which people are subject, rather it is a dynamic, ever-changing, unpredictable outcome of local interactions. This is not to say that the evolution of social order is random, for human beings do not operate independently. Human beings are social creatures who both enable and restrain the behaviour of other human 
beings. Along similar lines, Suchman (2011) contrasts the value of regarding the organisation as a machine vs regarding the organisation as a collective conversation. The latter metaphor discourages us from thinking about the organisation as a reified object. It encourages us to notice self-organising patterns of thinking and relating, and to encourage the same perspective taking in others. Boal and Schultz (2007) suggest that strategic leaders best fulfil their roles through dialogue and storytelling, by which means they are able to shape the evolution of agent interactions and facilitate the emergence of collective shared meanings. Baskin (2008) invites us to substitute the idea of complex adaptive systems for the idea of storied spaces, places where groups of people come to together to negotiate meaning. With reference to this perspective on change, Blomme (2012) lists six implications for effective leadership.

\section{Complex responsive thinking in the coach}

A complex responsive coach is likely to believe in the limitations of a systemic approach, in particular the idea that we can place boundaries around and within a system, and the idea that people's behaviours are controllable and/or predictable. The coach sees the organisation as a complex myriad of ever-shifting, dynamic and evolving relationships. The role of a leader is not to try and direct events, but to knowingly and purposefully participate in relationships in service of influencing the behaviour of others. The coach will pay attention to the enactment of power dynamics and the evolution of collective social identity. We might observe the coach encouraging the coachee to notice management efforts to direct and control outcomes and to hold lightly demands to implement change. Coach and coachee may explore the notion of identity, at the level of the individual and the collective, and notice how differences in identity manifest themselves and are addressed by those seeking to implement change. The coach will encourage the coachee to pay attention to quality of conversation, with reference perhaps to models of monologue and dialogue, and to become further aware of their own patterns of thinking and relating.

\section{Implications for practice}

In sharing some of these ideas over recent months with fellow coaches and academics, I have recognised an implicit assumption in others that these four perspectives on systems thinking constitute a linear pathway toward a more sophisticated and desirable coach practice model. Accordingly, I have been asked what value there is in spending time outlining how first- and second- order perspectives may manifest themselves in coaching? Why not 
instead focus on advocating complex systemic and/or complex responsive perspectives, and on providing case studies to illustrate how such perspectives translate into practice? This is a great challenge, and I will endeavour to respond to it in future writings, but the purpose of this paper is different. The purpose of this paper is to compare and contrast perspectives and to provide a simple framework through which practitioners can query and otherwise explore different manifestations of 'systemic coaching'.

The framework is necessarily simplistic. It is not being suggested that there exist 'first order systemic' coaches, 'second order systemic' coaches, 'complex systemic' coaches and 'complex responsive' coaches. Coaches are discouraged from categorising themselves in this way. The coach may more usefully invest time in querying their own coaching 'philosophy' (Jackson \& Bachkirova, 2019) in service of further clarifying for themselves their personal relationship with systems thinking. Similarly, in interpreting specific accounts of systemic coaching, it is unlikely that particular theories can be neatly classified under one of these four headings. The value of the framework lies in enabling the practitioner to discern the philosophy of the writer and to question the alignment of theory and practice.

Table 1 compares and contrasts some fundamental beliefs underlying each of the four hypothetical perspectives. Some coaches may readily identify with one of the four perspectives. Others may find themselves picking and choosing from different perspectives. This should not be surprising given the simple nature of the framework. The exercise is valuable, it is suggested, in prompting a more in-depth consideration of personal philosophy. 
Table 1. Beliefs underpinning four hypothesised perspectives

\begin{tabular}{llll}
\hline \multicolumn{1}{c}{$\begin{array}{c}\text { First order } \\
\text { systemic }\end{array}$} & \multicolumn{1}{c}{$\begin{array}{c}\text { Second order } \\
\text { systemic }\end{array}$} & \multicolumn{1}{c}{$\begin{array}{c}\text { Complex } \\
\text { systemic }\end{array}$} & \multicolumn{1}{c}{$\begin{array}{c}\text { Complex } \\
\text { responsive }\end{array}$} \\
\hline $\begin{array}{l}\text { Organisational systems } \\
\text { are real. }\end{array}$ & $\begin{array}{l}\text { Organisational systems } \\
\text { are real. }\end{array}$ & $\begin{array}{l}\text { Organisational systems } \\
\text { are real. }\end{array}$ & $\begin{array}{l}\text { Organisations are not } \\
\text { systems. }\end{array}$ \\
\hline $\begin{array}{l}\text { Systems can be broken } \\
\text { down into component } \\
\text { parts. }\end{array}$ & $\begin{array}{l}\text { Systems are complex, } \\
\text { problematical and } \\
\text { mysterious. }\end{array}$ & $\begin{array}{l}\text { To understand the } \\
\text { functioning of the } \\
\text { whole system requires } \\
\text { an exploration of local } \\
\text { interactions. }\end{array}$ & $\begin{array}{l}\text { The nature of human } \\
\text { interaction is too } \\
\text { unpredictable and } \\
\text { responsive to be } \\
\text { modelled. }\end{array}$ \\
\hline $\begin{array}{l}\text { Underlying principles } \\
\text { and rules can be } \\
\text { discerned. A leads to B } \\
\text { leads to C. }\end{array}$ & $\begin{array}{l}\text { Underlying principles } \\
\text { and rules can be } \\
\text { hypothesised }\end{array}$ & $\begin{array}{l}\text { Systemic patterns } \\
\text { emerge through social } \\
\text { interaction. }\end{array}$ & $\begin{array}{l}\text { Relational patterns } \\
\text { emerge through social } \\
\text { interaction. }\end{array}$ \\
\hline $\begin{array}{l}\text { It is possible to stand } \\
\text { outside a system and } \\
\text { diagnose its functioning. }\end{array}$ & $\begin{array}{l}\text { It is possible to stand } \\
\text { outside a system and } \\
\text { diagnose its functioning. }\end{array}$ & $\begin{array}{l}\text { Every agent in the } \\
\text { system plays a role in } \\
\text { the emergence of } \\
\text { outcomes. }\end{array}$ & $\begin{array}{l}\text { The organisation is not } \\
\text { a system but is part of } \\
\text { a wider myriad of } \\
\text { social relationships. }\end{array}$ \\
\hline
\end{tabular}

In Table 2, the four perspectives are compared and contrasted in respect of their translation into practice. Again, the purpose of the framework is to prompt coaches into questioning the way that they coach. This is 'process' according to Jackson and Bachkirova (2019) and it is useful to compare philosophy and process. Is the way I personally coach consistent with my espoused beliefs? Are the processes espoused by particular writers consistent with underlying theory?

The purpose of this paper is not to encourage practitioners to begin categorising themselves, other coaches, and writers, into one of four boxes. Rather it is to offer a simple framework/language to enable practitioners to talk about different aspects of systemic practice, a dialogue from which may emerge new insights as to how the industry generally might continue to adapt to a world that continues to evolve and change at a rapid pace. 
Table 2. Practices associated with four hypothesised perspectives

\begin{tabular}{|c|c|c|c|}
\hline \multicolumn{4}{|c|}{ Systemic Perspective } \\
\hline $\begin{array}{l}\text { First order } \\
\text { systemic }\end{array}$ & $\begin{array}{l}\text { Second order } \\
\text { systemic }\end{array}$ & $\begin{array}{l}\text { Complex } \\
\text { systemic }\end{array}$ & $\begin{array}{l}\text { Complex } \\
\text { responsive }\end{array}$ \\
\hline $\begin{array}{l}\text { Collect data (e.g. } \\
\text { organisation charts) to } \\
\text { understand how the } \\
\text { system works. }\end{array}$ & $\begin{array}{l}\text { Seek to understand } \\
\text { multiple perspectives on } \\
\text { organisation-as-system. }\end{array}$ & $\begin{array}{l}\text { Seek to understand } \\
\text { patterns of local } \\
\text { interaction and how } \\
\text { local interactions } \\
\text { converge into wider } \\
\text { patterns of behaviour. }\end{array}$ & $\begin{array}{l}\text { Seek to understand } \\
\text { patterns of social } \\
\text { interaction. Holding the } \\
\text { idea of system } \\
\text { boundaries lightly. }\end{array}$ \\
\hline $\begin{array}{l}\text { Focus on upgrading } \\
\text { component parts e.g. } \\
\text { individual leader } \\
\text { performance, individual } \\
\text { motivation etc ... }\end{array}$ & $\begin{array}{l}\text { Focus on mental models } \\
\text { (self and others). }\end{array}$ & $\begin{array}{l}\text { Focus on patterns of } \\
\text { local interaction. }\end{array}$ & $\begin{array}{l}\text { Focus on patterns of } \\
\text { social interaction and } \\
\text { the emergence of } \\
\text { identity and power } \\
\text { dynamics. }\end{array}$ \\
\hline $\begin{array}{l}\text { Collect feedback to } \\
\text { enhance individual } \\
\text { performance. }\end{array}$ & $\begin{array}{l}\text { Collect feedback to } \\
\text { deepen understanding of } \\
\text { system functioning. }\end{array}$ & $\begin{array}{l}\text { Collect feedback to } \\
\text { deepen understanding } \\
\text { of system functioning at } \\
\text { the micro-level. }\end{array}$ & $\begin{array}{l}\text { Collect feedback to } \\
\text { deepen understanding } \\
\text { of patterns of social } \\
\text { interaction. }\end{array}$ \\
\hline $\begin{array}{l}\text { Focus on building plans } \\
\text { and agreeing strategy. }\end{array}$ & $\begin{array}{l}\text { Consider plans and } \\
\text { strategies as ongoing } \\
\text { hypotheses. Be ready to } \\
\text { adapt and change. }\end{array}$ & $\begin{array}{l}\text { Consider plans and } \\
\text { strategies as local } \\
\text { responses to changes in } \\
\text { the system. }\end{array}$ & $\begin{array}{l}\text { Consider plans and } \\
\text { strategies as local } \\
\text { responses to wider } \\
\text { patterns of social } \\
\text { interaction. }\end{array}$ \\
\hline
\end{tabular}

\section{Conclusions}

More and more coaches, coach training houses, and authors are advocating a more systemic approach to coaching. Most of these voices urge both coach and leader to look beyond the dyadic relationship between coach and coachee, and interpersonal relationships within a team, to consider the impact of other variables in the 'system'. The system metaphor, however, can be used to depict quite different approaches to working with clients. First-order approaches depict the organisation as a coherent system operating to a set of rules. The coach and the manager can view the system from without and decide what changes they will make to the organisation for it to be more effective. Second-order approaches recognise that organisations are not tangible systems, rather they are mental constructs, and that it is therefore necessary to challenge the perspective of the outside observer. Approaches based on theories of CAS 
pay attention to local interaction and view broader patterns of behaviour as an outcome of myriad local interactions. The complex responsive perspective recognises the limitation of the system metaphor and focus on patterns of local interaction.

Change within the organisation as a whole is an outcome of all the multiplicity of local interactions taking place within it. These are four quite different philosophies, and because these perspectives on system are so different, it may be useful for us to make meaning of different systems approaches as we, the coaching industry, work out between us how we can be most useful in contributing to the success of organisations and society as a whole. In doing so, it may be useful for us to refrain from aligning ourselves too closely with a particular perspective and recognise that all four perspectives may prove useful when regarded as metaphor and deployed in different contexts. To focus instead on advocating a favourite perspective as being truly 'systemic' is to encourage convergence, at a time when we may more usefully engaged in a dialogic exploration of philosophies and perspectives that are different to our own.

\section{References}

Amerikaner, M. J. (1981). Continuing Theoretical Convergence: A General Systems Theory Perspective on Personal Growth and Development. Journal of Individual Psychology, 37(1), 31-53

Atkinson, C.J. \& Checkland, P. (1988). Extending the Metaphor "System". Human Relations, 10, 709-725

Bailey, K. (2005). Beyond System Internals: Expanding the Scope of Living Systems. Systems Research and Behavioral Science Systems Research, $22,497-508$

Baskin, K. (2008). Storied Spaces: The human equivalent of complex adaptive systems. Emergence: Complexity and Organization, 10(2), 1-12

Bateson, G. (1967). Cybernetic Explanation. The American Behavioral Scientist, 10(8), 29-32

Bertalanffy, L. von. (1968). General Systems Theory. USA: George Braziller.

Blomme, R.J. (2012). Leadership, Complex Adaptive Systems, and Equivocality: The Role of Managers in Emergent Change, Organization Management Journal, 9(1), 4-19

Boal, K. \& Schultz, P.L. (2007). Storytelling, Time, and Evolution: The role of strategic leadership in complex adaptive systems. The Leadership Quarterly, 18, 411-428

Bohm, D (1996). On Dialogue. Routledge, London 
Bovaird, T. (2008). Emergent Strategic Management and Planning Mechanisms in Complex Adaptive Systems. The Case of the UK Best Value initiative. Public Management Review, 10(3), 319 - 340

Cavanagh, M. (2006). Coaching from a Systemic Perspective: A complex adaptive conversation. In: D.R. Stober \& A.M. Grant, (Eds.), Evidence Based Coaching Handbook: Putting best practices to work for your clients. NJ: John Wiley \& Sons

Caws, P. (2015). General Systems Theory: Its Past and Potential. Systems Research and Behavioral Science Systems Research, 32, 514-521

Checkland, P. (1994). Systems Theory and Management Thinking. The American Behavioral Scientist, 38(1), 756-791

Checkland, P. (2000). Soft Systems Methodology: A Thirty Year Retrospective. Systems Research and Behavioral Science, 17, S11-S58

Checkland, P. (2012). Four Conditions for Serious Systems. Systems Research and Behavioral Science, 29, 465-469

Checkland, P. \& Haynes. M. (1994). Varieties of Systems Thinking: the case of Soft Systems Methodology. Systems Dynamics Review, 2/3, 189-197

Clutterbuck, D. (2007). Coaching the Team at Work. London: Nicholas Brealey International

Gell Mann, M. (1994). Complex Adaptive Systems. In: Complexity: Metaphors, Models and Reality. G. Cowan, D. Pines, D. Meltzer (Eds.). NY: Perseus

Gleick, J. (1988). Chaos: The making of the new science. London, UK: William Heineman

Grant, A.M. (2015). Coaching the brain: Neuro-science or neuro-nonsense? The Coaching Psychologist, 11(1), 31-37

Guy, J. (2018). Niklas Luhmann before Relational Sociology: The Cybernetics Roots of Systems Theory. Systems Research and Behavioral Science, $35,856-868$

Hawkins, P. (2004). A centennial tribute to Gregory Bateson 1904-1980 and his influence on the fields of organizational development and action research. Action Research, 2(4), 409-423

Hofkirtchner, W. \& Rousseau, D. (2015). Foreword to: L. von Bertalanffy. General Systems Theory, revised edition. USA: George Braziller.

Isaacs, W (1999). Dialogue and the Art of Thinking Together. NY: Currency Doubleday

Jackson, P. \& Bachkirova, T. (2019). The 3 Ps of supervision and coaching: Philosophy, Purpose and Process. In: E. Turner \& S. Palmer, (Eds.), The Heart of Coaching Supervision Oxon: Routledge 
Kamo, J. \& Phillips, F. (1997). The Evolutionary Organization as a Complex Adaptive System. PICMET '97: Proceedings of the Portland International Conference on Management of Engineering and Technology

Kobayashi, V.N. (1988). The Self-Reflexive Mind: The Life's Work of Gregory Bateson. Qualitative Studies in Education, 1(4), 347-359

Lane, D.C. \& Jackson, M.C. (1995). Onlv Connect! An Annotated Bibliography Reflecting and Diversity of Systems Thinking. Systems Research, 12(3), 217-228

Lawrence., P. (2015). Leading Change. How successful leaders approach change management. London: Kogan Page

Lepisky, V. (2018). Evolution of cybernetics: philosophical and methodological analysis. Kybernetes 47(2), 249-261

Malecic, A. (2017). Footprints of General Systems Theory. Systems Research and Behavioral Science Systems Research, 34, 631-636

Marion, R., \& Uhl-Bien, M. (2001). Leadership in Complex Organizations. The Leadership Quarterly, 12(4), 389-418

Miller, J.G. (1978). Living Systems. McGraw-Hill New York

Rousseau, D. (2015). General Systems Theory: Its Present and Potential. Systems Research and Behavioral Science Systems Research, 32, 522533

Schneider, M. \& Somers, M. (2006). Organizations as complex adaptive systems: Implications of Complexity Theory for leadership research. The Leadership Quarterly, 17, 351-365

Schwaninger, M. (2015). Research Paper Model-based Management: A Cybernetic Concept. Systems Research and Behavioral Science, 32, 564-578

Scott, D.C. (2016). Cybernetic Foundations for Psychology. Constructivist Foundations, 11(3), 509-517

Snowden, D.J. \& Boone, M.E. (2007). A Leader's Framework for Decision Making. Harvard Business Review, 85(11), 68-76

Stacey, R. D. (2012). Tools and techniques of Leadership and Management. Meeting the challenge of complexity. Abingdon, UK: Routledge

Stacey, R. D. \& Mowles, C. (2016). Strategic Management and Organisational Dynamics, $7^{\text {th }}$ edition. Harlow, UK: Pearson

Suchman, A. L. (2011). Organizations as Machines, Organizations as Conversations. Two Core Metaphors and Their Consequences. Medical Care, 49(12), S43-S48 
Ulrich, W. (2003). Beyond methodology choice: critical systems thinking as critically systemic discourse. Journal of the Operational Research Society, 54, 325-342

Varela, F. J., Maturana, H. R., \& Uribe, R. B. (1974), Autopoiesis: The Organization of Living Systems, Its Characterization and a Model. Biosystems 5(4), 187-196

Whittington, J. (2012). Systemic Coaching \& Constellations. An Introduction to the Principles, Practices and Applications. London: Kogan Page 


\title{
Using Group Coaching to Foster Reflection and Learning in an MBA Classroom
}

\author{
Erek J. Ostrowski \\ Boston, USA
}

\begin{abstract}
Group coaching may facilitate individual learning and change over time through the social processes of learning vicariously and learning through feedback. While anecdotal evidence shows there may be potential benefits of applying group coaching to a graduate school learning environment, there are several challenges which warrant consideration. After examining the findings of Ostrowski's (2018) study of the individual learning and change processes involved in group coaching, this paper outlines the role of group coaching in the design and implementation of a three-course series in a graduate business program. The personal reflections of students in the program shed light on group coaching's potential benefits, yet research is needed to substantiate their claims. The paper concludes by considering some of the challenges of applying group coaching in the classroom.
\end{abstract}

Keywords: coaching, group coaching, coach training, group learning, MBA education

\section{Introduction}

Although coaching has achieved a degree of acceptance as a method of enriching the learning experiences of MBA students, little is known about how group coaching can be used to foster learning and change in the classroom. After examining the findings of Ostrowski's (2018) dissertation study on the individual learning and change processes involved in group coaching, this paper outlines the role of group coaching in the design and implementation of a threecourse series in a graduate business program.

The paper begins with a brief exploration of the literatures on group coaching and coaching in MBA education. An overview of the design, findings, and application of Ostrowski's (2018) study follows. The paper then explores anecdotal accounts from students in the program which suggest that group coaching may hold significant value in this context. The paper concludes with an examination of some of the challenges involved in using group coaching in an MBA classroom, along with some tentative recommendations for those who might wish to continue the exploration. 


\section{Background}

Coaching is a collaborative process that supports personal reflection and meaning making, as well as the achievement of specific personal or professional objectives (Grant, 2006; Stelter, 2012; Stern, 2004). Group coaching can be defined as the application of coaching principles (such as active listening, meaningful questioning, designing actions, and managing accountability) to a small group, across multiple sessions, facilitated by a skilled professional, and in service of individual, collective, personal, and/or organizational learning and goals (Ostrowski, 2018). Despite the fact that dyadic (one-on-one) coaching is now supported by a substantive and growing research base, knowledge of the subdiscipline of group coaching is still in its infancy (O'Connor \& Cavanagh, 2017; Passmore \& Fillery-Travis, 2011). As a result, the literature base is sparse, and conceptions of group coaching differ according to a variety of theoretical perspectives.

Group coaching includes the coaching of intact work teams in organizations (team coaching), as well as coaching that involves other types of groups that may or may not have an organizational focus (Brown \& Grant, 2010; Thornton, 2010). To date, researchers have given more attention to the study of organizational team coaching than to unaffiliated group coaching in which group members share no close affiliation outside of the coaching group itself. However, in its latter form group coaching is becoming increasingly popular among practitioners and consumers (Britton, 2013; Ward, 2008).

O'Connor and Cavanagh (2017) argued that this type of group can benefit members by helping individuals draw from the challenges, learning, and experience of the other group members; and by linking individuals across their different situations and contexts. Although coaching in an unaffiliated group setting may appear to have much in common with organizational team coaching, the differences between these two practice environments (outlined below in Table 1) are worthy of consideration. 
Table 1. Unaffiliated Group vs. Work Team Coaching

\begin{tabular}{llll}
\hline Characteristics & Unaffiliated groups & Work teams & Noted by \\
\hline Focus & $\begin{array}{l}\text { Individual goals and } \\
\text { objectives }\end{array}$ & $\begin{array}{l}\text { Team-level goals shared } \\
\text { by all team members }\end{array}$ & $\begin{array}{l}\text { (Britton, 2010, 2013; } \\
\text { Cockerham, 2011; } \\
\text { Hawkins, 2017) }\end{array}$ \\
Relationships & $\begin{array}{l}\text { Bounded by the } \\
\text { coaching agreement }\end{array}$ & $\begin{array}{l}\text { Pre-established (co- } \\
\text { workers or team members } \\
\text { in the same organization) }\end{array}$ & (Britton, 2010, 2013) \\
Setting & $\begin{array}{l}\text { Diverse - not } \\
\text { necessarily } \\
\text { organizational or } \\
\text { business-focused }\end{array}$ & $\begin{array}{l}\text { Organizational—within a } \\
\text { single organization }\end{array}$ & (Britton, 2010, 2013; \\
Approacherham, 2011) & $\begin{array}{l}\text { Horizontal - } \\
\text { comparable vocational } \\
\text { levels; no } \\
\text { hierarchically senior } \\
\text { team leader or manager }\end{array}$ & $\begin{array}{l}\text { Vertical-process focuses } \\
\text { leard toward team }\end{array}$ & 2014) \\
\hline
\end{tabular}

\section{Unaffiliated Group Coaching}

Past studies have shown group coaching of this type to foster meaning making, social support, and positive lifestyle changes; while offering valuable opportunities to gain perspective and learn from peers (Stelter, Nielsen, \& Wikman, 2011; Van Dyke, 2012; Whitley, 2013). Stelter et al. (2011) found group coaching to facilitate meaning making and social support in elite high school athletes. Participants in the study were coached to surface their personal processes of meaning making formed through both experience and tacit knowledge. As a result, they learned to share their experiences, thoughts, and reflections as part of a peer dialogue, and to collaboratively form new stories about challenging events and circumstances to convey them in a new light. Van Dyke (2012) investigated the experiences of 21 executives who participated in 19 different virtual group coaching programs. Her findings indicated that participants used their coaching groups as structures of accountability, as sounding boards for the discussion of business challenges, 
and as opportunities to gain business knowledge and self-insight as part of a facilitated peer dialogue.

Whitley's (2013) action research study explored how group coaching can be designed to support and facilitate lifestyle changes in people with long-term health conditions (LTC). The coaching focused on facilitating interaction between group members, SMART goal setting and subsequent action, and the development of a supportive peer environment in which participants could reflect on their experiences. Participants reported that the group helped them practice the skills needed to achieve their goals, thereby supporting them to make changes in their lives, and to cope with and manage their health conditions.

These studies support the idea that group coaching has the potential to foster critical reflection and to serve as a catalyst for meaningful learning and change. However, little is known about how these experiential and social learning processes unfold in a group coaching setting, or about the different types of contexts and populations which stand to benefit from group coaching. Thus, a research study was conducted to learn more about group coaching as a setting for social and experiential learning and change (Ostrowski, 2018). That study, which formed the basis for the present article, examined entrepreneurs' experiences navigating challenges, which they might otherwise face in isolation, within the context of a coaching group. The findings (detailed below) showed that group members engaged in dynamic and impactful processes of learning and change that unfolded over time and through specific sequences of events.

\section{Coaching in MBA Programs}

An increasing number of top-ranked graduate business schools have turned to coaching as a way of attracting students and preparing them for the challenges of workplace leadership roles (Itah, August 5, 2013; Steiner, Dixon, $\&$ Watson, 2018). Typically, these MBA programs use professional one-onone coaching to help students develop their leadership and communication skills, and/or to help them clarify their career trajectories (Parker, Hall, \& Kram, 2008). The hope is that providing students with specialized and personal support will better prepare them for the responsibilities of management and help them stand out in an increasingly competitive marketplace.

Professional coaching resources can be a costly addition for MBA programs (Itah, August 5, 2013). As a flexible and cost-saving alternative, 
Parker et al. (2008) recommend peer coaching, in which students form dyadic coaching partnerships with one another in order to foster personal learning and leadership development. They propose that the steps students take toward building developmental relationships, coupled with the intrinsic rewards of the learning they experience, help them internalize peer coaching skills and apply them in the future. As a result, peer coaching provides opportunities for students to benefit from being coached. But through providing coaching for their peers, students also incorporate coaching into their management and leadership repertoire (Ladyshewsky, 2006; Parker et al., 2008).

Organizations are increasingly seeking to use coaching in ways that transcend performance management and that enable them to cope more effectively with a complex and uncertain business world (Grant, 2016; Stacey $\&$ Griffin, 2005). As a result, more are acknowledging coaching's value and potential as a tool for navigating cultural and organizational change (Bickerich, Michel, \& O'Shea, 2017). Thus, teaching and embedding coaching skills in organizational leaders has become a major focus in leadership development. While business schools have warmed to the idea of providing coaching as a resource for students, business students also need to learn coaching skills in order to be prepared for the demands of organizational leadership. Peer coaching, when effective, can service both of these needs.

Group coaching, meanwhile, holds promise for MBA education beyond the typical dyadic relationship between coach and student, or between student peers. As mentioned above, small-group coaching can be an effective alternative for fostering personal learning and development. Groups involve and can make use of relational learning and change mechanisms that are not available in dyads (O'Connor \& Cavanagh, 2017). Many of these mechanisms, such as those described by Yalom and Leszcz (2005), have been welldocumented in a clinical context and adapted for use in group coaching (Kets de Vries, 2011, 2014; Thornton, 2010).

In addition, group psychotherapy research has demonstrated that participants in group therapy benefit from meeting people with similar problems, comparing their difficulties with others, and realizing they are not alone in their experiences (Danino \& Shechtman, 2012; Holmes \& Kivlighan, 2000). In fact, individuals actually experience the therapy of other group members - both through observation and through direct participation (Holmes \& Kivlighan, 2000). Ostrowski's study (2018) demonstrated that similar social processes can unfold through group coaching. 


\section{The Research Study}

The purpose of Ostrowski's (2018) study was to examine group coaching as a setting for individual learning and change in entrepreneurs. Entrepreneurs engage with a different set of challenges from the organizationally employedone that requires different avenues for learning and problem solving (Brett, Mullally, O'Gorman, \& Fuller-Love, 2012). The turbulent and non-linear nature of entrepreneurial firms makes entrepreneurial learning (EL) less likely to occur in a planned or programmatic way, and more likely to occur experientially, through action taken in response to lived experiences and real world situations (Deakins \& Freel, 1998; Higgins \& Aspinall, 2011).

Critical reflection is key to translating these events into actionable learning opportunities (Argyris \& Schön, 1978; Mezirow, 1991), however many entrepreneurs work in relative isolation and lack opportunities to engage with peers in meaningful reflection and learning (Gumpert \& Boyd, 1984; Zhang \& Hamilton, 2009). Since learning in small firms hinges on social interaction (Higgins \& Aspinall, 2011), these pressures contribute to the need for entrepreneurs to seek out and find social contexts that can support their learning and development. Group coaching offers one such context. Ostrowski (2018) sought to explore entrepreneurs' experiences navigating challengesthat they might otherwise grapple with in isolation - within the context of a coaching group. The research question was, what does it mean to entrepreneurs to navigate their learning-related challenges in the context of a coaching group?

\section{Methods}

The study used a qualitative approach and narrative methods of inquiry and analysis. In general, qualitative approaches are suitable when the research goal is to understand the meaning that participants attribute to specific events, situations, or other social phenomena (Creswell, 2009; Maxwell, 2013). Qualitative research emphasizes individual meaning, and often seeks to render the complexity of lived experience (Creswell, 2009). Narrative methods are used to explore the stories or storied descriptions of events that take place in the lives of individuals (Pinnegar \& Daynes, 2007; Polkinghorne, 2010). As such, narrative researchers seek to gather rich, storied descriptions of events. Attention is placed on the sequence and consequences of human activity, and on the context(s) surrounding the production of storied data (Bailey \& Jackson, 2003; Riessman, 2008). 


\section{Recruitment}

Recruitment for the study involved finding and contacting coaches who provide group coaching services for entrepreneurs, and then inviting individual group members to participate in the study. The study applied two sets of inclusion criteria - one for the group coaching programs and one for their group members. The inclusion criteria for group coaching programs closely followed the definition of group coaching offered above (the application of coaching principles to a small group, across multiple sessions, etc.). In order to be considered for inclusion in the study, individual participants needed to own or operate their own small businesses or entrepreneurial ventures as defined by the 1996 European Commission on small and micro enterprises (Deakins \& Freel, 2012), have a financial investment at stake in their businesses (exposure to risk), and have a history of actively participating in an eligible group coaching program for at least two months and at least three group sessions over time.

Nine participants met the criteria for inclusion and chose to participate in the study. Two participated in a pilot study and seven in the main study. Data from one of the pilot interviews were later added to the main study, bringing the total number of participants in the main study to eight (five female and three male). Six participants in the main study were referrals from two different groups led by the same group coach. The other two were each referred by different coaches and participated in separate group coaching programs.

\section{Data Collection}

Data collection was accomplished via one-on-one, semi-structured narrative interviews with each participant. Six interviews were conducted faceto-face, and three (including two pilot interviews) were conducted via Zoom web conference (audio only). The interviews ranged from 60-96 minutes in length. The interview protocol for this study was designed according to Kvale's (2007) recommendations for conducting semi-structured life-world interviews, and Chase's (2003) advice on interview questions in narrative research.

\section{Analysis}

The data were interpreted using separate and sequential narrative/performative and thematic analytical methods (Braun \& Clarke, 2006; Polkinghorne, 1995; Riessman, 2008) to produce an in-depth, multidimensional understanding of the data. 
The goal of a narrative/performative analysis is to configure the data elements into an over-arching and emergent higher-order plot or explanatory story of each interview. Ostrowski reviewed the interview transcripts, noting speech elements and their use, "scenes" portraying unfolding action and its result, and relevant contextual information. He then developed rich explanatory stories supported by quotes and specific examples from the data. Such an analysis brings to the surface "truths unique in their particularity" and grounded in human experience (Josselson \& Lieblich, 2003).

In contrast, the product of thematic analysis is a set of common elements or categories that stretch across multiple stories, participants, and events (Riessman, 2003, 2008). Ostrowski followed Braun and Clarke's (2006) method; which involved coding the transcript data and searching for themes; then reviewing, defining and naming the themes and weaving them together to create an overall story of the analysis.

\section{Findings}

Group members were found to have engaged in dynamic and impactful processes of learning and change. The study revealed a range of possible process moves reflecting individual and social processes of learning and change that unfold over time and through specific sequences of events. Two broad types or categories of moves emerged from the data: moves that demonstrated learning vicariously and moves that demonstrated learning through feedback.

\section{Learning vicariously}

Participants described specific instances of becoming deeply involved in another group member's unfolding experience, learning from that involvement, and applying their learning in specific ways. Their stories illustrated three different "modes" of engagement with their peers' experiences: through empathy, challenge, and observation. The content of their vicarious learning also differed. Stories were reflective of learning that encompassed new theories of effective action, new business tactics, and/or the evolution of the entrepreneurs' entrepreneurial identities.

Participants' ways of engaging, coupled with the content of their learning, formed three distinct but related process moves with varying impacts in the participants' lives: 
- Learning new theories of effective action by engaging empathetically in another group member's transition, which enabled the participant to capitalize on a new business opportunity.

- Learning about one's entrepreneurial "self" by observing or challenging another group member's idea or decision, which strengthened the participant's claims to entrepreneurial identity.

- Learning new business tactics by observing another group member's idea, which led the participant to develop a new product for her company.

\section{Learning through feedback}

Entrepreneurs benefit in multiple ways from receiving feedback from other group members. The participants told stories about receiving feedback from others in the group, learning from this exchange, and applying their learning in specific ways. Their stories revealed at least three different types of feedback that the entrepreneurs received: acknowledging latent skills, legitimizing personal values, and distinguishing habitual behavior. As above, the content of their learning through feedback differed. The stories they told demonstrated learning about new strengths or capacities, achieving new clarity about priorities, and developing new self-awareness.

The type of feedback given and the content of participants' learning combine to form distinct but related process moves which all revolve around the notion of learning through feedback:

- Developing new strengths or capacities through receiving feedback that acknowledges latent skills, resulting in the pursuit of a new business opportunity, and the creation of a new reflective practice.

- Achieving new clarity about priorities through receiving feedback that legitimizes personal values, resulting in more time spent with family and new claims to entrepreneurial identity.

- Acquiring new self-awareness through receiving feedback that helps distinguish habitual behaviors, resulting in new ways of approaching work and new claims to entrepreneurial identity. 


\section{Implications for Coaches and Coaching Educators}

The study holds several implications for coaches and coaching educators, as described below. First, the findings help establish the validity of group coaching as a platform for supporting meaningful learning and change on multiple levels. Second, they help distinguish group coaching in relation to dyadic (one-on-one) coaching. Third, they help define the role of the coach in group coaching. And finally, they lend support to a long-term view of the group coaching process.

\section{Supporting Meaningful Learning and Change}

Group members navigated different processes of learning and change, driven by vicarious experience and direct feedback. The findings were reflective of both lower-level (adaptive) learning, and higher-level (exploratory) learning, as defined by the literature (Burgoyne \& Hodgson, 1983; Higgins \& Aspinall, 2011). Lower-level learning - responding to changes, correcting problems, adopting new ideas and tactics, and so on-is common for entrepreneurs. Higher-level learning, on the other hand, is rarer. It involves critically examining the values and assumptions that guide one's understanding of effective action. Higher level learning, in effect, involves "learning how to learn" from experience (Cope \& Watts, 2000), which can result in new selfawareness and personal understanding. The findings suggest that group coaching can help individuals develop the skills and resources necessary for higher-level learning by (a) introducing new information and perspectives that stimulate critical reflection, (b) creating a supportive atmosphere that nurtures introspection and insight, and (c) providing encouraging feedback from peers that can legitimize new insight and self-knowledge.

\section{Distinguishing Group Coaching from Dyadic Coaching}

The findings further distinguish the subdiscipline of group coaching relative to dyadic (one-on-one) coaching. At issue are the distinctions that make group coaching uniquely itself. This study shows that a number of social processes support or enhance coaching in a group context. Most importantly, participants' meaningful experiences involved learning from peer feedback or learning vicariously by engaging in peers' experiences. These defining moments stemmed from group members' interactions with each other, as opposed to their interactions with their coaches alone. Thus, in group coaching, the coaching relationship expands beyond the dyad to encompass the entire group. As Thornton (2010) argued, this provides wider opportunities for 
reflection and exchange, and allows for more direct and less threatening feedback between individuals who are relatively equal in power.

These conclusions underline the appropriateness of using group psychotherapeutic theory (Foulkes, 1948, 1986; Yalom \& Leszcz, 2005) as a lens for group coaching research, education, and practice-building on the work of Kets de Vries (2014) and Thornton (2010) in this vein. Research in this area has shown, for example, that group treatment allows clients to learn from both seeking and providing help (Holmes \& Kivlighan, 2000), and that individuals in group psychotherapy experience greater session depth when other group members engage in vicarious learning (Kivlighan, 2011). Knowledge of group psychotherapeutic theory and research helps shed necessary light on some of the distinguishing characteristics of unaffiliated coaching groups.

\section{Understanding the Role of Group Coach}

The defining characteristics of group coaching discussed above hold implications for the coach's role. Since the group context allows members to both seek help and provide it (Holmes \& Kivlighan, 2000), group members shift in and out of these roles at different times. Whereas dyadic coaching casts the coach in role of helper and the client in the role of coachee, group coaching requires the coach to be aware of group members' emergent identities as helpers, and in essence, to support and enable the helping process wherever it shows up in the group. For the coach, this means stepping back from the role of primary helper and focusing instead on holding (Winnicott, 1971) the group and on facilitating coaching competency in others. A central role of the group coach, then, is to enable group members to be successful in their roles as both coachees and peer coaches, and to encourage productive interaction and movement between these roles.

\section{Supporting Learning Over Time}

Finally, the findings support Stelter's $(2012,2014)$ view that the role of the group coach includes collaborating with group members to promote critical reflection, meaning generation, and the invention of new narratives that impact on identity and self-concept. Part of this process involves helping group members reflect on and make sense of their learning over time. There is some debate in the literature as to whether single-day or short-term interventions such as those studied by Barrett (2006), Kets de Vries (2005, 2011, 2014), and Ward (2008), should actually be considered group coaching. Although intervention

styles such as these promote quick results or "change in a single session" 
(Ward, 2008, p. 73), others have defined group coaching as something that specifically happens over time.

Thornton (2010), for example, stated that a multi-session format is necessary in order to reinforce and build on previous learning through continued reflection. Brown and Grant (2010) stressed the iterative nature of "idea development" over multiple sessions (p. 41), and Stelter et al. (2011) noted that engaging in multiple sessions over time helped participants develop durable social networks with their peers in the group. This study builds on the latter, long-term perspective. It supports the idea that multiple sessions over time allow for certain experiential and social learning processes to unfold that cannot possibly unfold in a single session. In other words, group coaching may best be conceived as an experiential and recursively organized phenomenon that allows for (a) the unfolding of experience over time and (b) the revisiting of experience and its meaning by group members.

\section{Applications in MBA Education}

These conclusions help to explain why and how group coaching holds promise as a method of helping graduate business students learn to engage thoughtfully and reflectively with peers as part of a learning dialogue. As stated above, the metacognitive processes involved in learning to coach one's peers hold additional promise for students as they prepare for leadership roles in a complex and volatile business environment. This raises the question of how group coaching can be incorporated successfully into MBA classrooms such that students receive both the personal benefits of receiving coaching and the knowledge and skills required to effectively coach others. However, the use of group coaching in MBA classrooms has received scarce attention from researchers. What impact can group coaching make when integrated into an MBA program? What do business students need to learn or master in order to become skillful group coaches themselves? The next section explores these questions through a brief case example outlining the application of group coaching in the design of a three-course professional practicum series in a graduate business program.

\section{Group Coaching Pilot Program}

The three-course professional practicum series is part of an early-career track MBA program at a small, private college in the Northeast United States. The purpose of the practicum is to help students learn to reflect critically on their early professional experiences, incorporate their learning into their 
emergent notions about who they wish to be as business leaders, and be prepared for the types of highly complex challenges they will face as managers. The practicum uses group coaching in the classroom as a way of helping students learn to reflect on and make meaning of their experiences, and to acquire specific coaching skills which are highly desirable in today's organizations. Vicarious learning and peer feedback are fundamental to the program's design, which is described below.

\section{Group Coaching Goals}

The primary goal of the group coaching was to help students reflect on and make meaning of their professional experiences in real time. As part of their MBA curriculum, students were required to obtain internships in professional organizations. Group coaching was used as a vehicle for expressing and talking about issues that arose out of these professional experiences (i.e., interpersonal challenges, self-advocacy, time management, decision-making, etc.). A secondary goal of the group coaching was to teach students to be effective coaches with one another, so that the coaching groups could function as robust learning environments in the classroom, and so that the students would acquire transferable coaching skills that would enhance their leadership and professional contributions in their places of work. The group coaching model used in the practicum was organized to help achieve these goals.

\section{Group Coaching Model}

The coaching model utilized a four-part design incorporating core coaching principles, relevant contextual knowledge areas, supervised practice, and reflective writing:

1. Core Coaching Principles. Six group coaching principles (Appendix A) formed a starting point for familiarizing the students with coaching. The principles are grounded in the literature and the International Coaching Federation (ICF) competency model ("Core Competencies," n.d.). The students' assignments included readings that directly addressed each competency.

2. Relevant Contextual Knowledge. Readings and in-class discussions of knowledge areas relevant to leadership, professionalism, and organizational life. These included personal purpose, emotional intelligence, gender, power, networking, organizational culture, and managing change.

3. Supervised Practice: 
a. Students were given time at each classroom session to meet in small groups in order to share their own experiences, learn from others' experiences, receive coaching and feedback from peers, and provide coaching and feedback to peers, under the supervision of an experienced group coach.

b. Classroom time was devoted to discussing and practicing the coaching principles, and to viewing coaching issues and situations through the lenses of the relevant contextual knowledge areas.

c. Classroom time was devoted to debriefing the students' internship and group coaching experiences, identifying important takeaways, action steps and commitments, etc.

4. Reflective Writing. The students were assigned a series of reflective papers to help them consolidate and apply their learning from the course.

\section{Preliminary results}

Anecdotal evidence from the students' reflection papers suggests that group coaching experiences present value in the development of early career MBA students' thinking about themselves, about others, and about enabling others to be effective in a professional setting:

"[My experiences in the group] helped me realize that I have the ability to determine what my 'perfect' is rather than setting the standard so high it is unattainable and unrealistic."

"The coaching groups pushed me to be open with my peers about my thoughts and struggles. In sharing my personal experiences, I often found that many of us were going through similar situations."

"The coaching groups allowed the class to create a community where we could express our thoughts and work to solve challenges. The coaching sessions often helped me to uncover a new way of thinking about a problem."

"As the year went on, I improved at following my curiosity to help uncover the underlying roots to a problem. It became more natural for me to ask open-ended questions, which pushed the 
thought process of my peers to approach problem-solving in new ways."

These results are highly encouraging. However, a more systematic and controlled study is needed to understand students' experiences more fully. Likewise, further research is needed to determine whether and how group coaching in an MBA classroom differs from the dyadic peer coaching studied by Parker and her colleagues (2008) in a similar setting. For example, what does the group environment provide in this setting that a dyad does not provide? Do the key characteristics of effective coaching groups differ from those of dyads? If so, how?

Potter (2017) showed that coach training may actually lead to growth in students' cognitive ability measured in terms of hierarchical complexity (vertical development). Could incorporating group peer coaching (as outlined above) into an MBA program contribute to students' vertical development? If so, how does their development compare with that of students in traditional MBA programs? Also, what design factors or best practices should be taken into account when incorporating group coaching into an MBA offering?

\section{Emergent challenges}

The pilot revealed several challenges as well, which must be considered when using group coaching in an MBA classroom setting. The potential for deep learning and change though group coaching is fundamentally connected to the creation of a safe, trusting, and intimate group environment (Kets de Vries, 2011; Thornton, 2010). A central challenge of using group coaching in the classroom involves building this kind of trust among student peers and ensuring psychological safety. Another challenge involves looking beyond the coaching dyad. Typically, coaching involves two people - a coach and a coachee. In group coaching, the coach (or group member taking on the coaching role) must access the collective resources of the larger group by engaging other group members in the process. This could include posing questions to the whole group to help illuminate one group member's coaching issue or asking other group members to share their own personal reflections in order to deepen one individual's coaching inquiry.

Consensus feedback holds special weight in a coaching group (Ostrowski, 2018). In other words, when a group is unanimous in their feedback to a specific group member, the message often holds more weight in the coachee's mind than if the same message were delivered by the coach alone. A third 
challenge of using group coaching in the classroom involves learning to actively leverage consensus feedback. Finally, and unsurprisingly, elevating students' group coaching skills can prove challenging. Participants in a coaching group must learn to focus on listening actively and creating a context of empathy and curiosity rather than on giving advice or "solving" their peers" problems. This can be difficult for students to grasp in the beginning. One solution is to model effective coaching behavior. This may provide a scaffolding (Wood, Bruner, \& Ross, 1976) to assist students as they work to increase their competency as new coaches.

\section{Conclusion}

Group coaching appears to facilitate individual learning and change over time through the social processes of learning vicariously and learning through feedback. Although coaching in general has achieved a degree of acceptance as a method of enriching the learning experiences of MBA students, most studies focus on providing one-on-one professional coaching for students or dyadic peer coaching in the classroom. Little is known about how group coaching can be used to foster learning and change in a similar setting. This paper reviews findings that group coaching can indeed foster rich learning and change in entrepreneurs outside of the classroom. However, it also strengthens the case for incorporating group coaching into graduate business programs and calls for additional research in this area.

\section{References}

Argyris, C., \& Schön, D. A. (1978). Organisational learning: A theory of action perspective. Reading, MA: Addison-Wesley.

Bailey, D. M., \& Jackson, J. M. (2003). Qualitative data analysis: Challenges and dilemmas related to theory and method. The American Journal of Occupational Therapy, 57(1), 57-65.

Barrett, P. T. (2006). The effects of group coaching on executive health and team effectiveness: A quasi-experimental field study (Doctoral dissertation). Retrieved from ProQuest Dissertations and Theses database. (UMI No. 3227469)

Bickerich, K., Michel, A., \& O'Shea, D. (2017). Executive coaching during organisational change: a qualitative study of executives and coaches perspectives. Coaching: An International Journal of Theory, Research and Practice, 11(2), 117-143. doi:10.1080/17521882.2017.1407806

Braun, V., \& Clarke, V. (2006). Using thematic analysis in psychology. Qualitative Research in Psychology, 3(2), 77-101. 
Brett, V., Mullally, M., O'Gorman, B., \& Fuller-Love, N. (2012). The role of action research in the development of learning networks for entrepreneurs. Action Learning: Research and Practice, 9(2), 125-143. doi:10.1080/14767333.2012.685699

Britton, J. J. (2010). Effective group coaching: Tried and tested tools and resources for optimum coaching results. Mississauga, Ontario: John Wiley \& Sons Canada.

Britton, J. J. (2013). From one to many: Best practices for team and group coaching. Somerset, NJ: John Wiley \& Sons.

Brown, S. W., \& Grant, A. M. (2010). From GROW to GROUP: Theoretical issues and a practical model for group coaching in organisations. Coaching: An International Journal of Theory, Research and Practice, 3(1), 30-45.

Burgoyne, J. G., \& Hodgson, V. E. (1983). Natural learning and managerial action: A phenomenological study in the field setting. Journal of Management Studies, 20(3), 387-399.

Chase, S. E. (2003). Learning to listen: Narrative principles in a qualitative research methods course. In R. Josselson, A. Lieblich, \& D. P. McAdams (Eds.), Up close and personal: The teaching and learning of narrative research (pp. 79-99). Washington, DC: American Psychological Association.

Cockerham, G. (2011). Group coaching: A comprehensive blueprint. Bloomington, IN: iUniverse.

Cope, J., \& Watts, G. (2000). Learning by doing - An exploration of experience, critical incidents and reflection in entrepreneurial learning. International Journal of Entrepreneurial Behavior \& Research, 6(3), 104-124. doi:10.1108/13552550010346208

Core Competencies. (n.d.). International Coach Federation. Retrieved from https://coachfederation.org/core-competencies

Creswell, J. W. (2009). Research design: Qualitative, quantitative, and mixed methods approaches. Thousand Oaks, CA: SAGE Publications.

Danino, M., \& Shechtman, Z. (2012). Superiority of group counseling to individual coaching for parents of children with learning disabilities. Psychotherapy Research, 22(5), 592-603. Retrieved from http://www.ncbi.nlm.nih.gov/pubmed/22694319

Deakins, D., \& Freel, M. (1998). Entrepreneurial learning and the growth process in SMEs. The Learning Organization, 5(3), 144-155. doi:10.1108/09696479810223428

Deakins, D., \& Freel, M. (2012). Entrepreneurship and small firms (6th ed.). Maidenhead, UK: McGraw-Hill. 
Foulkes, S. H. (1948). Introduction to group analytic psychotherapy. In S. L. Garfield \& A. E. Bergin (Eds.), Handbook of psychotherapy and behaviour change (3rd ed.). New York, NY: Wiley.

Foulkes, S. H. (1986). Group analytic psychotherapy: Method and principles. London, UK: Karnac Books.

Grant, A. M. (2006). An integrative goal-focused approach to executive coaching. In D. R. Stober \& A. M. Grant (Eds.), Evidence based coaching handbook: Putting best practices to work for your clients. Hoboken, NJ: John Wiley \& Sons.

Grant, A. M. (2016). The third 'generation' of workplace coaching: creating a culture of quality conversations. Coaching: An International Journal of Theory, Research and Practice, 10(1), 37-53. doi:10.1080/17521882.2016.1266005

Gumpert, D. E., \& Boyd, D. P. (1984). The loneliness of the small-business owner. Harvard Business Review, 62(6), 18-24.

Hawkins, P. (2017). Leadership Team Coaching: Developing Collective Transformational Leadership (3rd ed.). New York, NY: Kogan Page.

Higgins, D., \& Aspinall, C. (2011). Learning to learn: A case for developing small firm owner/managers. Journal of Small Business and Enterprise Development, 18(1), 43-57. doi:10.1108/14626001111106424

Holmes, S. E., \& Kivlighan, D. M. (2000). Comparison of therapeutic factors in group and individual treatment processes. Journal of Counseling Psychology, 47(4), 478-484. doi:10.1037/W022-OI67.47.4.478

Itah, M. (2013). Executive treatment before the title: Coaching in b-schools. Poets \& Quants. Retrieved from https://poetsandquants.com/2013/08/05/executive-treatment-before-thetitle-coaching-in-b-schools/

Josselson, R., \& Lieblich, A. (2003). A framework for narrative research proposals in psychology. In R. Josselson, A. Lieblich, \& D. P. McAdams (Eds.), Up close and personal: The teaching and learning of narrative research (pp. 259-274). Washington, DC: American Psychological Association.

Kets de Vries, M. F. R. (2005). Leadership group coaching in action: The Zen of creating high performance teams. Academy of Management Executive, 19(1), 61-76.

Kets de Vries, M. F. R. (2011). The hedgehog effect: The secrets of building high performance teams. San Francisco, CA: Jossey-Bass.

Kets de Vries, M. F. R. (2014). The group coaching conundrum. International Journal of Evidence Based Coaching and Mentoring, 12(1), 79-91. 
Kivlighan, D. M. (2011). Individual and group perceptions of therapeutic factors and session evaluation: An actor-partner interdependence analysis. Group Dynamics: Theory, Research, and Practice, 15(2), 147160.

Kvale, S. (2007). Doing interviews. Los Angeles, CA: Sage.

Ladyshewsky, R. K. (2006). Peer coaching: A constructivist methodology for enhancing critical thinking in postgraduate business education. Higher Education Research \& Development, 25(1), 67-84. doi:10.1080/13600800500453196

Maxwell, J. A. (2013). Qualitative research design: An interactive approach (3rd ed.). Thousand Oaks, CA: SAGE Publications.

Mezirow, J. (1991). Transformative dimensions of adult learning. San Francisco, CA: Jossey-Bass.

O'Connor, S., \& Cavanagh, M. (2017). Group and team coaching. In T. Bachkirova, G. Spence, \& D. Drake (Eds.), The Sage handbook of coaching. Thousand Oaks, CA: SAGE Publications.

Ostrowski, E. J. (2018). Coming in from the cold: The experience of group coaching as a setting for entrepreneurial learning and change. (Doctoral dissertation). Retrieved from ProQuest Dissertations and Theses database. (UMI No. 10746488)

Ostrowski, E. J. (2019). Crticial reflection in coaching. Unpublished manuscript.

Parker, P., Hall, D. T., \& Kram, K. E. (2008). Peer coaching: A relational process for accelerating career learning. Academy of Management Learning \& Education, 7(4), 487-503.

Passmore, J., \& Fillery-Travis, A. (2011). A critical review of executive coaching research: A decade of progress and what's to come. Coaching: An International Journal of Theory, Research and Practice, 4(2), 70-88. Retrieved from http://www.tandfonline.com/doi/abs/10.1080/17521882.2011.596484\#. U0LK9sda6-o

Pinnegar, S., \& Daynes, J. G. (2007). Locating narrative inquiry historically. In D. J. Clandinin (Ed.), Handbook of narrative inquiry: Mapping a methodology. Thousand Oaks, CA: Sage Publications.

Polkinghorne, D. E. (1995). Narrative configuration in qualitative analysis. International Journal of Qualitative Studies in Education, 8(1), 5-23. Retrieved from http://dx.doi.org/10.1080/0951839950080103

Polkinghorne, D. E. (2010). The practice of narrative. Narrative Inquiry, 20(2), 392-396. doi:10.1075/ni.20.2.11pol 
Potter, P. (2017). Becoming a coach: The transformative learning and hierarchical complexity of coaching students. (Doctoral dissertation). (UMI No. 10258038)

Riessman, C. K. (2003). Narrative analysis. In M. S. Lewis-Beck, A. Bryman, $\&$ T. Futing Liao (Eds.), The Sage encyclopedia of social science research methods (Vol. 1-3). Thousand Oaks, CA: Sage Publications.

Riessman, C. K. (2008). Narrative methods for the human sciences. Los Angeles, CA: Sage Publications.

Rogers, J. (2009). Coaching skills: A handbook(2nd ed.). Maidenhead: Open University Press.

Senge, P. M. (2006). The fifth discipline: The art and practice of the learning organization. New York, NY: Doubleday/Currency.

Stacey, R. D., \& Griffin, D. (2005). A complexity perspective on researching organizations: Taking experience seriously. London: Taylor \& Francis.

Steiner, S., Dixon, D. P., \& Watson, M. A. (2018). MBA coaching program: Best practices for success with limited resources. Management Teaching Review, 3(1), 86-97.

Stelter, R. (2012). A guide to third generation coaching: Narrativecollaborative theory and practice. Dordrecht, The Netherlands: Springer.

Stelter, R. (2014). Third generation coaching: Reconstructing dialogues through collaborative practice and a focus on values. International Coaching Psychology Review, 9(1), 51-66.

Stelter, R., Nielsen, G., \& Wikman, J. M. (2011). Narrative-collaborative group coaching develops social capital - a randomised control trial and further implications of the social impact of the intervention. Coaching: An International Journal of Theory, Research and Practice, 4(2), 123-137.

Stern, L. R. (2004). Executive coaching: A working definition. Coaching Psychology Journal: Practice and Research, 56(3), 154-162.

Stober, D. R., \& Grant, A. M. (Eds.). (2006). Evidence based coaching handbook: Putting best practices to work for your clients. Hoboken: John Wiley \& Sons, Inc.

Thornton, C. (2010). Group and team coaching: The essential guide. New York, NY: Routledge.

Van Dyke, P. (2012). Virtual group coaching: The experience of business professionals in the process. (Doctoral dissertation). Retrieved from ProQuest Dissertations and Theses database. (UMI No. 3546895)

Van Dyke, P. (2014). Virtual group coaching: A curriculum for coaches and educators. Journal of Psychological Issues in Organizational Culture, 5(2), 72-86. 
Ward, G. (2008). Towards executive change: A psychodynamic group coaching model for short executive programmes. International Journal of Evidence Based Coaching and Mentoring, 6(1), 67-78.

Whitley, S. (2013). Group coaching as support for changing lifestyle for those diagnosed with a long-term condition. International Journal of Evidence Based Coaching and Mentoring(Special Issue 7), 82-89.

Whitworth, L., Kimsey-House, K., Kimsey-House, H., \& Sandahl, P. (2009). Co-active coaching: New skills for coaching people toward success in work and life (2nd ed.). Boston, MA: Davies-Black.

Winnicott, D. W. (1971). Playing and reality. London, UK: Penguin.

Wood, D., Bruner, J., \& Ross, G. (1976). The role of tutoring in problem solving. Journal of Child Psychology and Child Psychiatry, 17, 89-100.

Yalom, I. D., \& Leszcz, M. (2005). The theory and practice of group psychotherapy. New York, NY: Basic Books.

Zhang, J., \& Hamilton, E. (2009). A process model of small business ownermanagers' learning in peer networks. Education + Training, 51(8/9), 607-623. 


\section{Appendix A: Coaching Principles}

Generate Dialogue (Senge, 2006)

- Suspend judgments and opinions

- Explore issues from multiple perspectives

- Nurture a collective understanding

- Facilitate meaning making

Listen Actively (Rogers, 2009)

- Be patient

- Let go of your own agenda

- Listen to what's not being said

- Show that you're listening and that you understand

Question Powerfully (Rogers, 2009)

- Ask open-ended questions

- Clarify understanding

- Deepen the inquiry

Reflect Critically (Ostrowski, 2019)

- Surface underlying beliefs and assumptions

- Focus on values

- Look inward

Design Actions (Stober \& Grant, 2006)

- Break large projects down into manageable chunks

- Find the highest leverage point

- What and by when?

Manage Accountability (Rogers, 2009; Whitworth, Kimsey-House, KimseyHouse, \& Sandahl, 2009)

- Track commitments

- Follow up on committed actions

- Address incompletions 


\title{
Book review
}

\section{Turner, T., Lucas, M. \& Whitaker, C. (2018). Peer Supervision in Coaching and Mentoring. A Versatile Guide for Reflective Practice. London: Routledge.}

\author{
Cat Dunne \\ Sydney, Australia
}

Earlier this year, a group of my fellow coaching peers invited me to participate in setting up a peer group supervision session. As we wanted the sessions to be valuable, we were fortunate that my individual coaching supervisor lent me a copy of this book, just to help us on our journey. It turned out to be extremely helpful and worthy of review.

Our engagement in a peer supervision process seems consistent with the greater acceptance of supervision that appears to exist within the coaching community, and coaches' increased participation in it. Interestingly, research has shown that peer supervision is the first experience of supervision for many coaches, principally because it is accessible and low cost (Lawrence \& Whyte, 2014).

Despite these advantages, drawbacks exist (Gray, 2017). For example, many coaches report that peer supervision tends to be unstructured, and its value diminished by factors such as lack of self-awareness amongst participants (e.g. blind spots) and a lack of coaching experience (Bachkirova, Jackson \& Clutterbuck, 2011). Anecdotally, the lack of structure in peer supervision appears to be a common experience amongst coaches, and I have direct experience of supervision sessions resembling informal chat groups.

Given this past experience, I found the book extremely helpful. In particular, I found Chapters 3 and 4 especially useful as they provided practical guidance on what ingredients and methods are needed to run an effective peer supervision session. For those looking to engage in one to one peer supervision practice, Chapter 3 provides insight into the mechanics of setting up an effective reflective practice. This chapter also discusses the critical factors in forming the relationship between a supervisor and a coach, the mechanics of the 
coaching process (location, format, duration etc.) and the importance of contracting boundaries for the coaching relationship and process. Chapter 4 covers group supervision, offering additional guidance on meeting structures and group meeting techniques, along with sample group contracting processes and templates. In setting up our own peer group supervision session, the contracting discussion guide helped us to agree on our supervision scope, boundaries, meeting process and roles. The time we spent on the initial contracting has enabled our supervision time to be effective and focused.

In Chapters 5 and 7 the principles behind contracting and ethics are explained. Both are an important aspect of the supervision relationship, enabling the creation of a reflective environment that fosters, trust, openness and psychological safety. For those new to coaching supervision, it is not always clear what issues to bring along for discussion. To assist with this, Chapter 7 explores coaching and mentoring dilemmas and provides an extensive range of case studies and dilemma scenarios that a coach may experience within their practice. In our own peer group, we have used some of the examples to help us engage and share key learnings and reflections from our practices. The discussions enable a pragmatic way to explore common tensions and challenges us to examine our boundaries.

Drawing on extensive experience gained from coaching practice, coach supervision, and coaching scholarship, the authors have done a wonderful job of co-creating an informative, practical resource for the benefit of coaching practitioners, supervisors, and internal HR and OD managers. This book guides practitioners on how to build and develop a range of individual and group reflective learning practices in an evidence-based way. In this way, the book helps to take peer supervision practice to new levels, allowing coaches to experiment with their eyes wide open, to collaborate and to learn with peers in a purposeful and effective way.

\section{References}

Bachkirova, T., Jackson, P. \& Clutterbuck, D. (2011). Coaching and Mentoring Supervision: Theory and Practice. McGraw-Hill: UK.

Gray, D.E. (2017). Towards a Systemic Model of Coaching Supervision. In T. Bachkirova, G. Spence \& D. Drake (Eds.), The SAGE Handbook of Coaching. SAGE: London (pp. 662 - 679).

Lawrence, P. \& Whyte, A. (2014). What is coaching supervision and is it important? Coaching: An international journal of theory, research and practice, $7(1), 39-55$. 


\title{
Book review
}

\section{Stout-Rostron, S. (2019). Transformational Coaching to Lead Culturally Diverse Teams. London: Routledge.}

\author{
Keegan Luiters \\ Sydney, Australia
}

The work that I do with individual leaders, teams and organisations is focused on helping teams work better as interdependent networks. As such, the opportunity to review this book was a welcome opportunity to explore the perspectives of an author whose experience and rigor could assist in my personal and professional growth.

A convergence of factors make this book increasingly relevant for coaching practitioners. First, there is an increased reliance on teams within organisations globally. Second, globalisation has changed the nature of those teams, such that they are often both culturally diverse and remote. Finally, organisations better understand that the maximisation of talent cannot occur without embracing diversity (e.g. cultural, gender, age) and more inclusive practices. Stout-Rostron points to these forces early in the book and notes that there is a need to "grasp the dramatic transformation of society and organisations driven by the "Fourth Industrial Revolution"' (p. 13). According to the author, working effectively with leaders, teams and organisations requires coaches to develop a firm grasp of the realities faced by those they seek to help.

In the first half of the book, Stout-Rostron presents the basic case for team coaching, with a succinct, yet thorough, summary of why and how team coaching is important for both teams and practitioners. Helpfully, this includes (in Chapter 4) an exploration of the author's own High-Performance Relationship Coaching Model, with a generous mix of case studies and practical reflections. This also includes (on page 48) an acknowledgement of scholarly influences underpinning the model, somewhat reflective of a "systemic-eclectic" approach to team coaching (Clutterbuck, 2010). With the introduction of each model, the reader is encouraged to engage in self-directed learning, such that s/he might deepen personal understanding of models as 
diverse as. Lencioni's Five Dysfunctions of a Team model (Lencioni, 2006) through to Spinelli's philosophical interpretation of existential phenomenology (Spinelli, 2010). Pleasingly, Stout-Rostron also overtly acknowledges the circular logic of systems thinking, such that her team coaching model explicitly presents team development as a dynamic, non-linear process. As the author notes, the "idea of circularity has had a strong influence on my team coaching model" (p. 45).

The second half of the book advocates strongly for the importance of diversity and culture. "The importance of coaches understanding diversity and culture, especially for team coaching, cannot be overemphasised" (p. 82). Whilst it has become a cliché to say that we live in a VUCA world (i.e. Volatile, Uncertain, Complex and Ambiguous), as a former colleague is fond of saying, "it's a cliché for a reason". With this VUCA reality in mind, I was fascinated to read Chapter 6 and learn about (for the first time) the African philosophical concept of "ubuntu" and, more specifically, absorb key aspects of an Ubuntu coaching model (as presented by contributor Dumisani Magadlela). For anyone looking for a non-Western approach to team coaching, underpinned by the principles of humanism, complexity and systems thinking, the Ubuntu model will be of great interest and the ancient African philosophies that inform it:

Ubuntu coaching is predicated on [the] core value system of humaneness and interrelationships. It is inherently systems-based meta-model of coaching. (p. 92)

As a first-generation Australian from South Africa, the chapter on Ubuntu coaching was especially salient. My enjoyment of it was partly related to my new learning and a recognition of my cultural heritage. But there was also something else, something holistic. It reinforced for me how beneficial it can be - as coaches - to value culture and diversity, such that we can work more effectively in organisations. After reading the book, I think there are opportunities for all coaches to do two things. First, to understand more fully the cultural influences that inform their world views. Second, to consider more culturally diverse approaches to coaching. To date, my experience in coaching has been informed predominantly by Western theories and models. But I know see that there is potential value to be gained from considering other cultural perspectives (e.g. African, Asian) as ways to understand the inherent complexity of teams and human interaction. 
Notably this book is relatively short (under 150 pages), yet it manages to capture and distil diverse perspectives. Indeed, any of the chapters could become the topic of a book all of its own. Stout-Rostron and the other contributing authors present a highly practical, well researched book that seems well suited to any coaching practitioner keen to develop their team coaching skills, irrespective of their commitment to cultural diversity. For those seeking specifically to embed cultural diversity in their approach, the book presents established and emerging coaching philosophies to complement their existing practices.

\section{References}

Clutterbuck, D., 2010. Coaching reflection: The liberated coach. Coaching: An International Journal of Theory, Research and Practice, 3(1), pp.73-81. Lencioni, P., 2006. The Five Dysfunctions of a Team. New York: John Wiley \& Sons.

Spinelli, E., 2010. Existential coaching. In E. Cox, T. Bachkirova, \& D. Clutterbuck, The Complete Handbook of Coaching. London: Sage. (pp. 94-106). 


\title{
Book Review
}

\section{Oades, L.G., Siokou, C.L. \& Slemp, G.R. (2019). Coaching and Mentoring Research: A Practical Guide. London: Sage.}

\author{
Gordon Spence \\ Sydney, Australia
}

It is not difficult to find instructive texts on the basics of behavioural and social science research. Such books typically provide comprehensive, highly detailed descriptions of the numerous ways a researcher might choose to think about their research, and then organise themselves to undertake it. Whilst such detail is undoubtedly helpful, it can also make 'standard' texts rather dense and not so user-friendly.

Coaching and Mentoring Research: A Practical Guide is a different sort of research text. Some of those differences become apparent at first point of contact. The front cover is somewhat understated, utilising a simple image and basic colour palette. More significantly, whilst it is quite compact (less than 250 words), a quick glance at the table of contents suggests that it is not insubstantial. As such, my initial impressions of this book were that I was about to embark on a brief, manageable but highly stimulating read. As it happened, this turned out to be the case.

The book is organised into four parts. In Part 1, the reader is encouraged to consider what it is to be a coaching and mentoring researcher; what might be beneficial about it, how one can ensure high impact, who might be useful to work with (in a research team), what pitfalls are good to avoid, and what theories of knowledge (epistemologies) might guide the process.

With those foundations attended to, Part 2 focuses on the various phases of the research process. In effect, this section is a beginning-to-end description of what happens when conducting research. It presents nine chapters that briefly describe how researchers approach key tasks such as choosing a research methodology, framing research questions, reviewing literature, collecting and analysing data, and disseminating research findings. 
To my mind, these chapters are noteworthy for two reasons. First, they are brief. Whilst it would be possible to dedicate many more pages to each of the nine topics, the authors have resisted any urge they might have had to do so. Instead, the aim of this section appears to be to inform and raise the awareness of readers about critical issues. Second, the structure of the chapters reflects the basic philosophy of coaching. The self-directed learning of readers is supported throughout via the use of the GROW model, with technical information accompanied by questions designed to stimulate thinking, identify options, promote action, and build knowledge along the way.

Having overviewed the major elements of the research process, Part 3 and Part 4 give attention to the use of quantitative methods (Part 3), and qualitative methods (Part 4). As many readers will know, these are significant topics in any text focused on research. Indeed, entire books are often dedicated to describing quantitative and qualitative methods, with an intricacy that can be challenging to even experienced researchers.

However, in Coaching and Mentoring Research: A Practical Guide, consideration of these topics is made manageable, with a succession of short (810 page) chapters to stimulate the reader's thinking and build awareness of relevant issues. For example, in Chapter 15, the reader is encouraged to think about what type of research study they wish to undertake, and what methods are best suited to the research questions being posed (rather than methods that readers might feel naturally inclined towards). Much like earlier chapters, the information is presented in a way that is designed to assist decision making (again using GROW), with further reading and resources offered at the end of each chapter.

Tellingly, one of the shortest chapters in the book (Chapter 19) is on statistical methods. The authors begin by acknowledging that, "many people are not confident with mathematics in general, and this is true also for applied statistical methods at higher education level" (p. 161). Then, rather than attempting any sort of exploration of statistical methods, the authors encourage readers to self-assess their confidence levels with statistics (using a series of self-set scaling questions), before encouraging them to identify options that can help develop their statistical knowledge and skills. All-in-all, only six pages are used for this most vexed of research topics, which I found to be written in a way that was both empathic and empowering.

The appeal of this book will depend greatly on each reader's level of research experience. For highly experienced, widely published researchers, 
there may be minimal value. However, for novice and less experienced researchers (e.g. students) or infrequent researchers (who need a refresher), this book has much to offer. It may also be of interest to practicing coaches and mentors who would like to be more informed consumers of published scientific research.

As should be apparent by now, this book does not set out to catalogue all that needs to be known about the production of high-quality coaching and mentoring research. Those with more granular information needs should look elsewhere. What it does do is provide the reader with a good, manageable introduction to research theories and practice. The authors seem acutely aware that "research" is a confronting idea for many people and possibly even alienating. As such, they write in a way that should feel empowering to readers, and most likely make important contributions to their future research efforts. 